\section{ECONGTOR}

Make Your Publications Visible.

\section{A Service of}

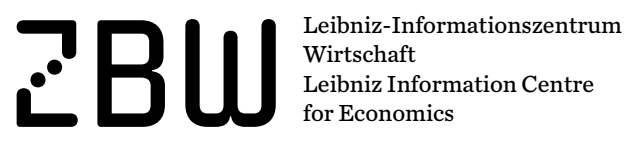

Demir, Ishak; Eroglu, Burak A.; Yildirim-Karaman, Secil

\title{
Working Paper \\ Heterogeneous effects of unconventional monetary \\ policy on bond yields across the euro area
}

LEAF Working Paper Series, No. 19-06

Provided in Cooperation with:

Lincoln Economics and Finance Research Group (LEAF), Lincoln International Business

School, University of Lincoln

Suggested Citation: Demir, Ishak; Eroglu, Burak A.; Yildirim-Karaman, Secil (2019) :

Heterogeneous effects of unconventional monetary policy on bond yields across the euro area, LEAF Working Paper Series, No. 19-06, University of Lincoln, Lincoln International Business

School, Lincoln Economics and Finance Research Group (LEAF), Lincoln

This Version is available at:

http://hdl.handle.net/10419/211493

Standard-Nutzungsbedingungen:

Die Dokumente auf EconStor dürfen zu eigenen wissenschaftlichen Zwecken und zum Privatgebrauch gespeichert und kopiert werden.

Sie dürfen die Dokumente nicht für öffentliche oder kommerzielle Zwecke vervielfältigen, öffentlich ausstellen, öffentlich zugänglich machen, vertreiben oder anderweitig nutzen.

Sofern die Verfasser die Dokumente unter Open-Content-Lizenzen (insbesondere CC-Lizenzen) zur Verfügung gestellt haben sollten, gelten abweichend von diesen Nutzungsbedingungen die in der dort genannten Lizenz gewährten Nutzungsrechte.
Terms of use:

Documents in EconStor may be saved and copied for your personal and scholarly purposes.

You are not to copy documents for public or commercial purposes, to exhibit the documents publicly, to make them publicly available on the internet, or to distribute or otherwise use the documents in public.

If the documents have been made available under an Open Content Licence (especially Creative Commons Licences), you may exercise further usage rights as specified in the indicated licence. 


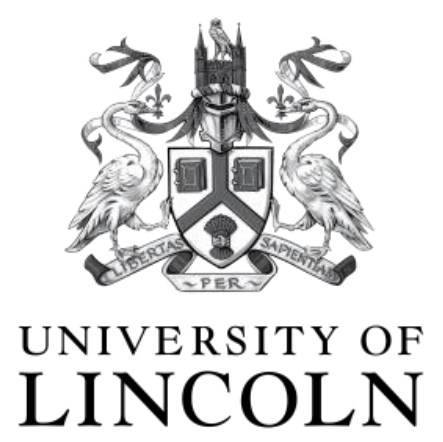

\title{
๑INCOLN E CONOMICS $₫$ ND FINANCE
}

\section{LEAF Working Paper Series}

\author{
No. 19-06
}

Heterogeneous effects of unconventional monetary policy on bond yields across the euro area

Ishak Demir

Burak A. Eroglu

Secil Yildirim-Karaman 


\title{
Heterogeneous effects of unconventional monetary policy on bond yields across the euro area *
}

\author{
İshak Demir ${ }^{\dagger}$ Burak A. Eroğlu; Seçil Yıldırım-Karaman ${ }^{\S}$
}

November 2019

\begin{abstract}
This paper investigates the impact of European Central Bank's unconventional monetary policies between 2008-2016 on the government bond yields of eight European Monetary Union countries and up to eleven different maturities. In identifying this impact, it adopts a novel econometric approach that combines data-rich dynamic factor analysis and VAR with heteroskadasiticy based identification. This novel approach allows a single model to estimate the impact of a common unconventional monetary policy shock across different countries, maturities, yield components and over time. The results identify a significant and substantial impact for all countries and all maturities in the sample. The evidence also suggests that the impact was stronger and persistent in the periphery countries which have higher financial distress, uncertainty, country risk and lower liquidity. When we decompose the impact into separate yield components, we find that unconventional shocks decreased the common market component of the yields in all countries. As for the risk component, unconventional policies decreased it for the periphery countries permanently at the cost of a small increase in the core countries, as consistent with the international portfolio balance channel. These findings contribute to the literature by providing a comprehensive characterization of the impact of unconventional monetary policies for different economic environments.
\end{abstract}

Keywords: Unconventional monetary policy, ECB, QE, international monetary transmission, portfolio balance, cross-country difference, yield curves, risk premia

JEL Classification: C38, E43, E52, E58, F42, G12

\footnotetext{
*We would like to thank to Refet Gürkaynak, Barbara Rossi, Haroon Mumtaz, Anna Galvao, Yunus Aksoy, Kıvanç Karaman and seminar participants at Advances in Applied Macro-Finance Conference at Bilgi University, Asset conference at Athens University of Economy and Business, University of Lincoln and Nazarbayev University for suggestions and comments.

${ }^{\dagger}$ Corresponding author.University of Lincoln, United Kingdom. E-mail: idemir@lincoln.ac.uk

${ }^{\ddagger}$ İstanbul Bilgi University, Turkey. Email: burak.eroglu@bilgi.edu.tr

${ }^{\S}$ Altınbaş University, Turkey. Email:secil.yildirim@kemerburgaz.edu.tr
} 


\section{Introduction}

Unconventional policies introduced during the Great Recession have redefined the toolbox of monetary policy, and played a major role in the recovery that followed. Despite their importance, however, we are still far from a complete understanding of their impact. One challenge in this endeavour is their short history, and the limitations it imposes on the available data. A second issue is that the standard tools that macroeconomists have developed to identify the impact of conventional monetary policies are not well suited for unconventional ones. Consequently, most existing studies provide a partial picture of their impacts, focusing on individual countries, specific channels, or specific time framest.

This study contributes to the literature by offering a comprehensive account of the impact of European Central Bank's (ECB) unconventional monetary policies on the government bond yields between January 2008 and November 2016 and a discussion of cross-country differences in responses. In particular, we estimate the impact of the ECB's unconventional monetary shocks for eight different countries and up to eleven different maturities using high frequency data. For each country and maturity, the model also allows decomposing the total effect of the unconventional policy shocks into separate effects on the common market, risk and term structure components of the bond yields and tracking the persistence of these effects over time. This comprehensive treatment is made feasible by a novel econometric model that combines a dynamic factor model, heteroskedasticity based identification, and a VAR model. The estimation results provide strong support for the effectiveness of the unconventional policies. In particular, for the common market component of the bond yields, we find unconventional policies reduced them for all countries and all maturities. As for the risk component, unconventional policies reduced them significantly for peripheral economies, while increasing them slightly for the core countries. This result implies that the sovereign risk in the periphery economies is shared by the core economies through ECB's asset purchases.

The unconventional monetary policies investigated in this study are expansion of central banks' balance sheets through quantitative easing (QE), extensive liquidity provision, and forward guidance ${ }^{2}$. These policies were introduced when short-term nominal interest rates in developed economies hit the zero lower bound in the early phases of the Great Recession, leaving little room for conventional monetary policy. Finding themselves in an unchartered territory, central banks in developed countries experimented with the new monetary policy instruments, with little past experience to rely on.

We investigate the impact of unconventional monetary policies based on the experience of EMU

\footnotetext{
${ }^{1}$ For example Fratzscher et al. $(2016)$, Chen et al. $(2012)$ and IMF $(2013)$ discuss that the size of the effects depends on the specific characteristics of the UMP programme implemented.

${ }^{2}$ See Haldane et al. (2016), Joyce et al. (2012), Cecioni et al. (2011).
} 
countries. This choice is motivated by the unique structure of the EMU, where the decisions of a single central bank affects bond yields across different countries and maturities. We adopt a novel econometric approach that captures this structure, and exploits the variation it offers. The event days in the sample are ECB's policy announcement days between 3 January 2008 and 25 November 2016. The model estimate the impact of unconventional shocks on these days on 80 different government bond yield series, spanning Germany, France, Austria, Netherlands, Belgium, Italy, Portugal and Spain and maturities ranging between 1 to 30 years.

The econometric model works in three steps. In the first step, relying on a dynamic factor model, we estimate three common factors for the 80 bond yield series for the different countries and maturities. These three common factors respectively capture the common market, risk and the term structure components of the bond yields in the euro area 3 . Reducing the 80 yield series into three common factors allows estimating a single model for the EMU while preserving the variation across countries and maturities.

In the second step, we estimate the impact of unconventional monetary policy shocks on each of the common market, risk and term structure factors. In these estimations, we rely on a VAR model with heteroskedasticity based identification which relies on the assumption that volatility of the policy shocks are relatively higher on the announcement days 4 . Heteroskedasticity based identification allows addressing the measurement issue $5^{5}$ and time window selection problem ${ }^{6}$ for unconventional policy shocks. The VAR model, in turn, allows estimating the impulse response functions, and hence measuring the persistence of the shock rather than the instantenous effect. One concern with the estimation is that on some of the event days there were both unconventional and conventional monetary policy shocks. Since we are interested in identifying the impact of unconventional monetary policy shocks, we include controls for the conventional policy shock:7.

Finally, in the third stage, for each country and each maturity, we back out the responses of common market, risk and term structure components of the bond yields to unconventional monetary policy shocks. To do so, we multiply the impulse responses of each of the three components

\footnotetext{
${ }^{3}$ These factors are not same with the canonical affine term structure studies in the finance literature named first three factors level,slope and curvature.

${ }^{4}$ See Rigobon and Sack (2003) and Wright (2012) for a detailed account of heteroskedasticity based identification

${ }^{5}$ For unconventional shocks, it is difficult to measure the market expectation before the policy announcement, and calculate the unexpected shock component. Consequently, event study method, which is commonly used to identify news and monetary policy shocks at high-frequency in the literature, does not address this problem for unconventional monetary policy shocks. Whereas heteroskedasticity based identification sidesteps this problem, because identification comes from the increase in volatility on the policy announcement days.

${ }^{6}$ Because unconventional policies are difficult to interpret and analyze, it takes time for the market to price them. Event study method requires selecting a time window for the pricing. A narrow time window may fail capture the full effect of the policy, while a wide window may contaminate its effect with other shocks, (Martin and Milas (2012) and Gagnon et al. (2011)). In heteroskedasticity based identification, on the other hand, the window is identified by the model, based on the changes in volatility.

${ }^{7}$ For conventional monetary policy shocks, we rely on the Euro Area Monetary Policy Event Study Database developed by Altavilla et al. (2019).
} 
obtained in the second step with the factor loadings obtained in the first step. Consequently, we are able to drive a complete characterization of the impact of common unconventional monetary policy shocks across countries, maturities, yield components and over time.

The results provide strong support for the effectiveness of unconventional monetary policy. We find that unconventional policy shocks decrease bond yields for all countries and all maturities. In other words, the unconventional policies were successful in easing financial distress across the board. With respect to cross-country variation, we find that the impact is stronger and more persistent in the periphery countries than that in the core countries. When we correlate the impact with country specific variables, we find that the impact is greater for higher levels of financial stress, uncertainty, country risk, financial depth and access and lower levels of liqudity. These patterns suggest that the policies were more effective where they were needed the most, and where financial markets were deep enough to let them work.

When we decompose the overall impact of unconventional policies into their impacts on the common market, risk and term structure components, we find that the impact mainly works through the first two. For the common market component, we find that the unconventional policies decrease the yields for all countries, with stronger effects on core countries. As for the risk component, the yields decrease significantly in the periphery countries and increase slightly in the core countries. This significant decrease in the yields of periphery countries which have relatively higher risk premia is consistent with the impact of the portfolio balance channel of monetary transmission.

The contribution of the paper to the literature builds on the novel econometric approach. To the best of our knowledge, our study is the first to employ dynamic factor analysis, heteroscedasticity based identification and VAR methodologies in the same model to investigate the impact of unconventional policies. In the existing literature, one vein investigates the impact of unconventional monetary policies through the event study method. In this vein, Glick and Leduc (2012), Krishnamurthy and Vissing-Jorgensen (2011), Gagnon et al. (2011) investigate the impact of these policies for the US and Falagiarda and Reitz (2015), Eser and Schwaab (2016), Fratzscher et al. (2016) and Chadha and Hantzsche (2018) for the euro area. While our findings on the effectiveness of the policies are consistent with these studies, the heteroscedasticity based identification we adopt avoids some of the pitfalls associated with measuring unconventional policy shocks. Wright (2012) and Rogers et al. (2014), on the other hand, employs heteroscedasticity based identification with VAR, but estimate separate models for each country and use the data for only some of the maturities. In our analysis, the dynamic factor model in the first step allows decomposing bond yields into three components that capture common market movements, risk and term structure in the euro area and estimating the impact for all countries and all maturities in a single model without heavy parameterisation. It also decreases the model uncertainty caused by omitted variables, unobservable factors and lagged endogeneity and therefore provides a reliable forecast for 
the persistence of the monetary policy impact. Consequently, we are able to exploit the unique structure of the EMU and engage in cross country comparisons within Europe.

The rest of the paper proceeds as follows. Section 2 provides a background on the ECB's unconventional monetary policy programme. Section 3 introduces the econometric model and section 4 the data set. Section 5 presents and discusses the results. Section 6 explores the policy implications and concludes.

\section{ECB's unconventional monetary policy and its transmission mech- anism}

\subsection{Euro area monetary policy programme during global financial crisis}

During the global financial crisis first FED and BOE and later ECB decreased the short-term nominal interest rates to zero. The persistence of the recession despite the low level of short-term interest rates raised questions about the conventional wisdom regarding monetary policy. Financial markets became distressed and the long-term interest rates increased in the US, UK and Europe. 30-year government bond return in the US increased by 200 basis points from December 2008 to December 2009. In the EA, 10-year government bond returns for Italy, Portugal and Spain increased, respectively, by around 300, 900 and 200 basis points from 2010 to 2012. In the same period, uncertainty in financial markets also increased significantly. In response, FED and BOE initially relied on direct quantitative easing $8^{8}$ to alleviate financial market stress and stimulate the economic activity. ECB differed from FED and BOE because it initially implemented indirect quantitative and credit easing and started direct quantitative easing in 2015.

The ECB sharply decreased the policy interest rate in the early 2009 and then gradually brought it down to zero. Simultaneously, ECB adopted unconventional policy measures such as extensive liquidity provision to the banking system, asset purchase programs, negative deposit facility rate and forward guidance.

-Figure 1 around here-

To increase liquidity provision to the banking system and loanable funds available to investors ECB took six unconventional policy measures (see Figure 1). It provided unlimited credit to banks at a fixed interest rate which is referred to as fixed rate full allotment (FRFA) in late 2008, expanded the range of eligible assets that could be used as collateral in refinancing operations (COLL), conducted longer term refinancing operations to support bank lending (LTRO) in 2009, targeted longer term refinancing operations to provide financing to credit institutions for periods of up to

\footnotetext{
${ }^{8}$ First, FED implemented QE in 2008, then BOE in 2009 and finally ECB in 2015.
} 
four years (TLTRO) in 2014, conducted swap lines with other central banks to increase liquidity provision in foreign currencies (FOR), conducted covered bond purchase programs which supports the functioning of the covered bond market and is important for bank financing (CBPP) between 2009-2014. These tools also signalled ECB's commitment to future low interest rates.

To mitigate the risk in the euro area, ECB introduced Securities Market Programme (SMP) in May 2010. This program aimed to reduce the sovereign bond spreads in the financially stressed EMU countries by purchasing their government bonds. ECB terminated SMP and adopted outright monetary transactions (OMT) in September 2012. This new program also aimed to reduce sovereign spreads in the risky EMU countries by purchasing their government bonds maturing in 1 to 3 years. These measures contributed to the size of ECB's balance sheet only moderately since they were sterilized and their volumes were relatively small.

The ECB announced an expanded asset purchase programme (APP) in January 2015 to stimulate economic activity and increase the inflation rate back towards its target. Under this programme, the ECB purchased bonds issued by the governments of EMU countries, European institutions and non-financial corporations. The size of the balance sheet of the ECB significantly increased with the adoption of the expanded APP.

ECB decreased the deposit facility rate to zero in November 2012 and made it negative in November 2014. Negative deposit facility rate means that the banks that deposit money in certain accounts at the ECB have to pay for it. The aim of this policy rate cut was to ensure price stability over the medium term and stimulate economic recovery by reducing the borrowing costs for the investors and consumers.

Using forward guidance policies the ECB provided information about the Governing Council's intentions about the expected future path of the key interest rates and the horizon of its asset purchase programme. It began using forward guidance in July 2013 when the ECB announced that the interest rates would remain low for an extended period of time. Forward guidance policies aimed to reduce the distress in the financial markets by reducing the uncertainty about the future stance of the monetary policy.

All unconventional policy actions described above might have affected the economy through signaling, liquidity premium and credit channels. In addition to these channels, SMP and OMP programmes aimed to affect the economy through portfolio balance and risk channels. In particular, purchasing particular securities of the riskier countries decreases their returns which causes investors to shift towards riskier assets. This shift, in turn, increases the asset prices and decreases the interest rates in the EA. 


\subsection{Transmission mechanism of UMP}

Unconventional policies implemented during the global financial crisis changed the conventional wisdom about the monetary transmission process. Below, we review the possible channels through which these policies might have affected financial markets and economic activity. We focus on several transmission channels that are relevant for financial markets without claiming to be exhaustive.

Signaling channel works through the extra information provided by the central bank about the future path of the policy rate. When central bank announces its intention to keep the short-term interest rates at low levels in the future, it is perceived as a signal by the market, which in turn causes a decline in the long-term bond returns. This channel is related to the uncertainty channel. Announcements of asset purchases which signal that interest rates will remain at the lower bound for a long period of time reduce the uncertainty about the future path of the policy rates. The effectiveness of the channel depends on the communications about the operations and their credibility .

Portfolio balance channel works through the imperfect substitutability between assets of different maturities, asset classes and countries. When the central bank purchases specific financial assets, it changes their availablity to the investors. This change, in turn, affects their yields. Investors rebalance their portfolios towards assets that offer a better risk-return trade-off, which in turn decreases the yields of those assets as wel?

Liquidity channel is relevant when liquidity is limited and financial markets become dysfunctional. When central bank purchases long-term securities and increases bank reserves, liquidity increases and markets function better. In turn, asset prices increase and liquidity premium that had increased falls (Joyce et al. (2011) ).

Confidence channel works when financial and economic outlook is subject to uncertainty. Market participants are affected by high volatility in the financial markets which induces them to scale their investments back. QE reduces macroeconomic uncertainty and increases confidence in the financial markets by reducing the risk of an economic downturn. This decrease in uncertainty, in turn, increases real economic activity.

Bank lending channel or credit channel works through the impact of policy decisions on the supply of credit. This impact is driven by financial incompleteness and the imperfect substitutability of

\footnotetext{
${ }^{9}$ In the standard asset-pricing framework, reallocation of assets between the central bank and the investors is neutral and does not affect the bond prices Woodford (2012). In a world with frictionless financial markets, term premia and prices are determined by the risk characteristics of the bonds and the risk aversion of the investors, which do not depend on the amount of bonds. Portfolio policies may have an effect in the presence of economic frictions such as preferred-habitat demand of investors, limits to arbitrage of different maturities, liquidity and collateral services (see Hamilton and Wu (2012), Gertler and Karadi (2011) Vayanos and Vila (2009))
} 
the bank loans (Kashyap and Stein (2000) Gräb and Żochowski (2017) and Buch et al. (2018)). In particular, businesses and consumers that rely on bank loans cannot easily replace them with other types of financing. Hence, a reduction in the credit supply causes a decline in consumption and investment. An expansionary unconventional monetary policy increases bank reserves and results in an increase in the loan supply. The size of the impact depends on the characteristics of the banks such as capitalization, asset size, and liquidity. Banks with high capital and liquidity ratios benefit more from the QE.

The impacts of the transmission channels discussed above overlap which makes it difficult to separate one from the other. The effectiveness of these channels depend on the specifics of the policies, the design of asset purchase programs, and the structure of the economy and financial system (see Haldane et al. (2016)). In this study, we investigate the impact of unconventional policies, the variation in impact across countries, and how this variation relates to the frictions in the financial system.

\section{Model and identification scheme}

In this section, we discuss the methodology for obtaining the impulse response functions of the EA sovereign bond yields to the unconventional policy shocks by the ECB. For this purpuse, we rely on a dynamic factor model together with heteroscedasticity based identification. Heteroscedasticity based idetification was introduced by Wright (2012) to identify the impact of monetary policy shocks. To do so, two separate VAR models are estimated for the policy announcement days and non-policy days. This framework, however, is only suitable for low dimensional VAR models since the number of announcement days is limited.

In this study, we evaluate the impact of unconventioal monetary shocks on 80 sovereign government bond yields for eight EMU countries. The large number of yield series make it infeasible to rely on heteroscedasticity based identification, due to the degrees of freedom issue discussed above. To overcome this problem, we adopt a three-stage procedure. In the first stage, we apply a dynamic factor model for dimension reduction and obtain a smaller set of dynamic factors. The second stage employs heteroscedasticity based identification on these factors to derive the impulse response functions (IRF). In the last stage, we back out the IRFs for the observed series from the IRFs of the dynamic factors.

\subsection{Dynamic factor model}

Let $N$ vector $Y_{t}$ stack all sovereign government bond yields, and $N_{1}$ vector $X_{1, t}$ include other exogenous covariates at time period $t=1,2, \cdots, T$, respectively. Each variable in $Y_{t}$ can be defined as $Y_{i, t}$ for $i=1,2, \cdots, N$. Consequently, the model that relates the observable variables $Y_{t}, X_{1, t}$ 
and the latent factors $F_{t}$ can be illustrated as follows:

$$
\begin{aligned}
Y_{i, t} & =\beta^{\prime} X_{1, t}+\lambda_{i}^{\prime} F_{t}+e_{i, t} \quad \forall i=1,2, \cdots, N \\
\Phi(L) F_{t} & =\epsilon_{t}
\end{aligned}
$$

where $\lambda_{i}$ is a $1 \times r$ vector of the factor loadings for each variable $i=1,2, \cdots, N, \beta_{1}$ is the vector of the coefficients of the covariates $X_{1, t}, F_{t}$ is a $r$ vector of static factors and $e_{i, t}$ is the residuals for all $i=1,2, \cdots, N$ in the factor model. Additionally, we assume a VAR structure for the factors $F_{t}$ where $\Phi(L)$ is the lag polynomial that governs the VAR model and $\epsilon_{t}$ is a r vector of innovations. Note that we impose $r<N$ to achieve dimension reduction. We try to elaborate the selection of $r$ in the results section. This factor model can be written in matrix notation as the following:

$$
Y=X \beta+F \Lambda^{\prime}+e
$$

where $Y$ and $e$ be $T \times N$ matrices of observations and residuals, respectively. $F$ is $T \times r$ matrix of the static factors, $\Lambda$ is $r \times N$ matrix that concatenates the factor loadings and $X_{1}$ is $T \times N_{1}$ matrix of exogenous covariates. Note that we can also write this model in the difference form: $\Delta Y=\Delta X_{1} \beta+\Delta F \lambda^{\prime}+\Delta e$. This notation is particularly important since we utilize the principal component $(\mathrm{PC})$ method to extract the factors. In order to employ the PC technique, the observable variables should be stationary Bai and $\mathrm{Ng}(2013)$. However, we can recover $F_{t}$ by integrating the estimated factors from the differenced mode 10 .

Before employing PC on the observed bond yields, we need to remove the covariates from $Y$. These covariates contain the implied stock market volatility index(VIX) that captures the global financial turmoil and economic risk and 10-years rate on U.S. government bonds.Having these indicators is crucially important to disentangle exogenous innovations to ECB's policy from the yield responses to global uncertainty and Fed's actions which have large influence on global financial conditions. Consider the model $\Delta Y=\Delta X_{1} \beta+u_{t}$ where $u_{t}=\Delta F \lambda^{\prime}+\Delta e$. We first obtain the residuals from this regression, say $\hat{u}_{t}=\Delta Y_{t}-\Delta X_{1, t} \hat{\beta}$ where $\hat{\beta}$ is the vector of the OLS estimates. As a result, we can use $\hat{u}_{t}$ instead of $\Delta Y_{t}$ to obtain the factors, since $\hat{u}_{t}$ does not contain any information shared with the covariate vector $X_{1, t 1}$ asymptotically. We denote the estimated $r$ principle components from $\hat{u}_{t}$ as $\Delta \hat{F}_{t}$. Integrating these principle components, we get the $r$ estimated factors, namely $\hat{F}_{t}$.

\subsection{Heteroscedasticy based identification}

Utilizing the estimated factors, we use heteroscedasticity based identification that exploits the volatility difference between the announcement and non-announcement days. This section follows Wright s (2012), which introduced the method.

\footnotetext{
${ }^{10}$ The details of the PC method can be found in Stock and Watson (2002).
} 
Let $\hat{F}_{t}$ be the estimated $\mathrm{r}$ factors estimated as described in the previous section. Further, we assume that the dynamic structure of $\hat{F}_{t}$ is governed by equation (2):

$$
\Phi(L) \hat{F}_{t}=\epsilon_{t} \quad \text { for all } t=1, \ldots, T
$$

The standard identification procedure in VAR models relies on the factorization of the variancecovariance matrix of the reduced form error terms. In other words, the identification is constructed on the second moment of the error terms. In contrast, heteroscedasticity based identification builds the identification procedure on the level of the reduced form innovations. The basic structure is given as follows:

$$
\epsilon_{t}=\sum_{i=1}^{k} R_{i} \eta_{i, t}
$$

where $\eta_{i, t} \mathrm{~s}$ are $k$ independent shocks and $r \times 1$ vector $R_{i}$ is constant weight of each shock. In this setup, each shock may correspond to an economic or financial element that affects the factor structure with different weights. For instance, we assume that the first shock, $\eta_{1, t}$, to be the monetary policy shock. $R_{1}$ quantifies the impact of this shock. The ordering of the shocks does not matter since the shocks are not directly associated with the variables in $\hat{F}_{t}$. Rather, they are associated with other economic or financial elements. Moreover, we assume that $\eta_{1, t}$ has zero mean with a variance of $\sigma_{\eta_{1}, 1}^{2}$ on announcement and $\sigma_{\eta_{1}, 0}^{2}$ on non-announcement days. For the other structural shocks $j=2, \ldots, k$, we assume $\sigma_{\eta_{j}, 1}^{2}=\sigma_{\eta_{j}, 0}^{2}$. In words, the policy announcements only influence the volatility of monetary policy shock while the variances of other shocks remain constant.

This setup requires two separate VAR models for the announcement and non-announcement days. For this purpose, we define an announcement day dummy pol $_{t}$, where pol $_{t}=1$ if $t$ is an announcement day and $p_{t}=0$ otherwise. Accordingly, we denote two mutually exclusive information set as $D_{0}=\left\{t \in \mathbb{N}:\right.$ pol $\left._{t}=0\right\}$ and $D_{1}=\left\{t \in \mathbb{N}:\right.$ pol $\left._{t}=1\right\}$ for non-announcement and announcement days, respectively. Using these information sets, the two VAR models are:

$$
\begin{aligned}
& \text { Model 0: } \Phi^{(0)}(L) \hat{F}_{t}=\epsilon_{t} \quad \text { for all } t \in D_{0} \\
& \text { Model 1: } \Phi^{(1)}(L) \hat{F}_{t}+\beta_{2} X_{2, t}=\epsilon_{t} \quad \text { for all } t \in D_{1}
\end{aligned}
$$

where we assume that the same lag truncation for $\Phi^{(0)}(L)$ and $\Phi^{(1)}(L) . \quad X_{2, t}$ is the vector of the policy surprise series that are used for concentrating out the impacts of the exogenous conventional policy shocks11. Let $\Sigma_{1}$ be the $r \times r$ dimensional variance-covariance matrix of $\epsilon_{t}$ on the announcement days and $\Sigma_{0}$ be the $r \times r$ dimensional variance-covariance matrix on the non-

\footnotetext{
${ }^{11}$ Because the monetary policy meeting days in our sample also include conventional monetary policy decision, we control for their impact by including exogenous measures of conventional policy surprises in the model. We estimated our model without conventional monetary policy decisions and we found no significant changes in our results.
} 
announcement days. The difference of the variance-covariance matrices on the announcement and non-announcement days can be represented as:

$$
\Sigma_{1}-\Sigma_{0}=\left(\sigma_{\eta_{1}, 1}^{2}-\sigma_{\eta_{1}, 2}^{2}\right) R_{1} R_{1}^{\prime}
$$

where we normalize $\sigma_{\eta_{1}, 1}^{2}-\sigma_{\eta_{1}, 2}^{2}$ to 1 , since $R_{1} R_{1}^{\prime}$ and $\sigma_{\eta_{1}, 1}^{2}-\sigma_{\eta_{1}, 2}^{2}$ cannot be separately identified. In order to estimate the vector $R_{1}$, we will use the following optimization problem proposed by Wright (2012):

$$
\hat{R}_{1}=\underset{R_{1}}{\operatorname{argmin}}\left[\operatorname{vech}\left(\hat{\Sigma}_{1}-\hat{\Sigma}_{0}\right)-\operatorname{vech}\left(R_{1} R_{1}^{\prime}\right)\right]^{\prime}\left[\hat{V}_{0}+\hat{V}_{1}\right]^{-1}\left[\operatorname{vech}\left(\hat{\Sigma}_{1}-\hat{\Sigma}_{0}\right)-\operatorname{vech}\left(R_{1} R_{1}^{\prime}\right)\right]
$$

$\hat{\Sigma}_{1}$ is the estimated variance-covariance matrix of reduced form error terms in Model $1, \hat{\Sigma}_{0}$ is estimated variance-covariance matrix of reduced form VAR residuals in Model $0, \hat{V}_{1}$ is variancecovariance matrix of $\hat{\Sigma}_{1}$ and $\hat{V}_{0}$ is variance-covariance matrix of $\hat{\Sigma}_{0}$. After we obtain an estimate for $R_{1}$, we can use it to compute the impulse response of each factor to the monetary policy shock.

\subsection{The impulse response functions}

In this subsection, we describe how we obtain the impulse response functions (IRF) for the observable variables. For this purpose, we first generate IRFs for the factor model, and then compute the IRFs for the variables in $Y_{t}$. First, suppose that the estimated full sample VAR is given as:

$$
\hat{F}_{t}=\hat{\Phi}_{0}+\hat{\Phi}_{1} \hat{F}_{t-1}+\hat{\Phi}_{2} \hat{F}_{t-2}+\ldots+\hat{\Phi}_{p} \hat{F}_{t-n}+\hat{\epsilon}_{t}
$$

where $p$ is lag length which is selected by Bayesian information criterion. We can write this estimated model in terms of Vector Moving Average representation:

$$
\hat{F}_{t}=\hat{\epsilon}_{t}+\hat{\Theta}_{1} \hat{\epsilon}_{t-1}+\hat{\Theta}_{2} \hat{\epsilon}_{t-2} \cdots
$$

with $\hat{\Theta}_{i}=\sum_{j=1}^{i} \hat{\Theta}_{i-j} \hat{\Phi}_{j}$ for all $i=1,2, \ldots$. The $h$ period ahead impulse response of the $i$ th variable to monetary policy shock can be computed as following:

$$
\frac{\partial \hat{F}_{i, t+h}}{\partial \eta_{1, t}}=I R F_{h, i} \text { for } i=1,2, \cdots, r
$$

where $I R F_{h, i}$ is the impulse response of the $i^{\text {th }}$ factor to the one standard deviation monetary policy shock and $I R F_{h}=\hat{\Theta}_{h} \times \hat{R}_{1}$. However, the goal is to derive the impulse response functions for the observed series in $Y_{t}$. We can reconstruct these impulse responses by simply multiplying $I R F_{h}$ with $\Lambda$, that is $\widetilde{I R F}_{h}=\Lambda^{\prime} I R F_{h}$. Note that $I R F_{h}$ is a $r \times 1$ vector and $I \tilde{R} F_{h}$ is a $N \times 1$ vector.

The next step is constructing the confidence intervals for the impulse responses. To derive the intervals, we use stationary block bootstrap of Politis and Romano (1994) combined with the Kilian 
(1998) bias adjustment. The bootstrapping procedure is described in the A.

Notice that our identification scheme relies on the difference between the variance of the reduced form residuals from announcement and non-announcement days. In order to check this condition, we apply Box's m test Box (1949). This test is based on the hypothesis that two (or more) variancecovariance matrices are equal to each other, that is $H_{0}: \Sigma_{0}=\Sigma_{1}$ vs $H_{0}: \Sigma_{0} \neq \Sigma_{1}$. The associated test statistic can be constructed with the following likelihood function:

$$
\log L=(T-2) \log (|S|)-\sum_{i=0}^{1}\left(T_{i}-k\right) \log \left(\left|\hat{\Sigma}_{i}\right|\right)
$$

where, $S=\frac{\sum_{i=0}^{1}\left(T_{i}-k\right) \hat{\Sigma}_{i}}{T-2 k}$ is pooled variance and $T_{i}$ is the sample size of each model and $k$ is number of parameters estimated in each mode 12 . Then, we can use the test statistic below:

$$
\begin{aligned}
B M=(1-h) \log L & \sim \chi^{2}\left(\frac{r(r+1)}{2}\right) \\
& \text { and } \\
h & =\frac{2 r^{2}+3 r-1}{6(r+1)}\left[\sum_{i=0}^{1}\left(\frac{1}{T_{i}-k}\right)-\frac{1}{T-2 k}\right]
\end{aligned}
$$

We rely on bootstrap inference for this test, since the number of announcement dates is small. We describe the bootstrap routine for this test in the A.

In this test, the null hypothesis of variance equality is rejected if $B M>\chi^{2}\left(\frac{r(r+1)}{2}\right)$ or $B M>C V_{\alpha}\left(B M^{*}\right)$ where $C V_{1-\alpha}\left(B M^{*}\right)$ is the $(1-\alpha)-t h$ quantile of the bootstrap empirical distribution.

\section{Data and summary statistics}

Our data sample is a daily balanced panel which consists of 80 time series and runs from 3 January 2008 to 25 November 2016 13 . It covers from one to thirty year maturity fixed-zero-coupon bond yields for 8 EMU countries: Austria, Belgium, France, Germany, Italy, Netherlands, Portugal and Spain 14 . Bond yield data is taken from Thomson Reuters Database. We also include EA aggregate 5-year and 10-year bond yields data from ECB as average yields for the Euro Area.We use the implied stock market volatility index VIX index from CBOE to control for market fear and global risk aversion and 10-years rate on U.S. government bonds as exogenous control variables.

\footnotetext{
${ }^{12}$ We assume equal $k$ for model 1 and 0 . If they are unequal (if different lag truncation is used), then the procedure should be adjusted accordingly.

${ }^{13}$ The weekends and holidays are removed from the sample.

${ }^{14}$ Our sample starts from 2008, since it is possible to construct a balanced dataset after this date. Greece and Ireland are dropped from the sample due to the lack of data
} 
We cover all monetary policy announcements by the ECB since Jan 2008 including speeches, press conferences, and press release ${ }^{15}$. On announcements days, conventional policies, unconventional policies or a mix of the two could be announced. To control for the impact of conventional policy announcements, we include 1 month OIS rate change in the VAR analysis, relying on the data from the Euro Area Monetary Policy Event Study Database 16 .

-Figure 2 around here-

Figure 2 shows the movements in 10-year sovereign bond yields. Except for the sovereign debt-crisis period, yields are highly correlated and move together. This pattern suggests a strong common market factor, arguably driven by the common exchange rate and the single monetary policy. After mid-2010, Italy, Portugal and Spain diverged from the core countries as a result of the increase in the risk and term premia (Ángel García and Gimeno (2014)). The yields for these countries began to decrease following ECB's announcement of the OMT programme ${ }^{17}$ and converged to the core economies in 2014 with the PSPP announcements. The trajectory of the yields suggests that ECB intervention successfully led to a decline in the risk premium in the distressed sovereign markets.

Table 1 shows the summary statistics for the first differences of the 10-year bond yields for each country on the policy and non-policy days. Unconditional mean and volatility of daily changes in yields on policy dates are higher than those on non-policy dates. As expected, the largest fall in the yields is observed on the unconventional policy announcement days ${ }^{18}$ In contrast, the changes in the core countries' yields are insignificant on unconventional policy announcement days, suggesting a heterogenous impact across EMU countries.

- Table 1 around here-

\section{Empirical results}

In this section, we first present the estimated factors and their loadings and interpret them economically. Second, we present the evidence on the contribution of each factor to the overall impact of the monetary policy shocks. Third, we present the results for the impact on maturities and the term structure of the interest rates. Finally, we show the cross-correlations between country level responses and observed country-specific characteristics and discuss the relevant monetary policy

\footnotetext{
${ }^{15}$ The ECB's policy announcement days are listed in Table B.1 in B

16 Altavilla et al. (2019). We use the rate change in the press release window, since it provides information only about the policy decision itself and not the related discussion.

${ }^{17}$ ECB President Mario Draghi made the "Whatever it takes." speech on 26 July 2012 followed by the official announcement of the OMT Programme in early August 2012.

${ }^{18}$ Portuguese yields fell by 204 basis points in May 2010 with the SMP announcement and Italian and Spanish yields fell by 81 and 90 basis points respectively in August 2011 with the SMP extension for Italy and Spain.
} 
transmission channels.

\subsection{Interpretation of the estimated factors}

We estimate that the three common factors explain about $70 \%$ of the variation in the yields. Figure 3 plots $R^{2}$ ordered by countries and maturities.

-Figure 3 around here-

The relative importance of the three factors varies across countries and maturities. They explain over $80 \%$ of the variation in the longer maturities and between $10-50 \%$ of the variation in the shorter maturities. Interestingly, the idiosyncratic component explains the highest share of the variation on the short-end of the yield curve, and the common market factor explains only about $25 \%$ of the variation.

Following McCracken and $\mathrm{Ng}(2016)$ we also calculate marginal $R^{2}$ s to see the corresponding series that load most heavily on each factor. The results are presented in Table 2 .

-Table 2 around here

-Figure 4 around here-

The first factor is associated with the core countries' medium and long-term yields with marginal $R^{2}$ s close to 0.80 . Figure $5 \mathrm{a}$ shows the close overlap between factor 1 and 10 -year bond returns in the core countries and suggests that factor 1 can be interpreted as the common market factor. The loading approach, which estimates the sensitivity of the bond returns to each factor, also suggests the same interpretation. The estimated loadings for factor 1, presented in Figure 4, are similar across core countries for maturities greater than a year 19

-Figure 5 around here-

The second factor captures the differences between the core and distressed countries with marginal $R^{2}$ s close to 0.55 . Figure $5 \mathrm{~b}$ provides evidence for this interpretation, by plotting the second factor together with the risk premiums of the 5 -year bond returns in the periphery countries relative to the German bonds. Between 2010 and 2014, the long term government bond returns in Italy, Spain and Portugal diverged from the returns in Germany due to the concerns about the sustainability of government debt. The second factor, which is close to zero except for this period, also increases after 2010, peaks in 2012 and decreases until 2014. This close overlap suggests that the second factor can be interpreted as the risk premium in the EMU countries and henceforth will

\footnotetext{
${ }^{19}$ Except for some of the 1-year bond yields, changes caused by the first factor are almost constant for all maturities, with some differences between core and distressed countries.
} 
be referred to as the risk structure factor.

The third factor captures the term structure with marginal $R^{2}$ of 0.18 . Figure $5 \mathrm{c}$ plots the third factor together with the difference between 30-year and 2-year government bond returns in the periphery countries. The spread between the short-term and the long-term bond returns increased after the onset of the global financial crisis, decreased after the ECB introduced unconventional policy measures, and increased again after the sovereign debt crisis. Factor 3 follows the same patterns, especially for Portugal until 2014. Based on this close relationship, we refer to Factor 3 as the term structure factor.

\subsection{Impulse response analysis}

In this section, we first verify the identification condition of the monetary policy shocks in the model by testing whether the variance-covariance matrices of the two regimes are different from each other. As we discussed in Section 3.3. we employ the Box's M test to verify this condition. We find that the Box's M statistic (BM statistic) is 2604.5 with a bootstrap critical value of 787.7 and bootstrap $\mathrm{p}$ value of 0 . Hence, there is strong evidence that the variance-covariance matrices are different for policy and non-policy days.

We next investigate the impact of unconventional monetary policy shocks on the EA 5 and 10year bond yields to normalize the monetary policy shock. Figure 6 plots the estimated responses of the bond yields to an expansionary monetary policy shock with a $95 \%$ bootstrap confidence interval. The identified monetary policy shock is normalized to lower EA 5-year yields by 50 basis points20. The shock also lowers the EA 10-year bond yields, but the magnitude of the impact is slightly smaller. The half-life of the estimated impulse responses for EA yields are about 2 months.

Below, we first discuss the impact of this normalized policy shock on the estimated factors. Second, we show the impact on the market component, risk structure and term structure of the yields. Third, we investigate the composite effect of the normalized policy shock on bond returns and the persistence of the responses for maturities from 1 to 30 years. Finally, we show that the initial and time-lagged responses of the yield curves for each country.

-Figure 6 around here-

\subsubsection{The impact on the different components of bond yields}

Before we present the results for the composite impact of unconventional policy measures at the zero lower bound, we review their impact on the common market, risk and term structure compo-

\footnotetext{
${ }^{20}$ We normalize the shock for the 5-year yield as it is at the midpoint of yield curve. ECB mainly targets bonds with 2-10 years maturity when implementing unconventional monetary policies.
} 
nents of the bond yields. We then discuss the role that each individual factor played in the overall impact of the shock.

Figure 7 shows the responses of the three factors to a normalized unconventional monetary policy shock. The factors that capture the common market component and the risk structure of the bond returns, factors 1 and 2, respond strongly and significantly. The response of factor 3, the term structure factor, is also significant but weaker than the responses of first two.

-Figure 7 around here-

We obtain the impulse responses for the common market component of the bond yields by multiplying the impulse response function of factor 1 , the common market factor, with its loadings. Common market factor increases in response to a normalized unconventional monetary policy shock. The loadings for factor 1 are negative for all countries and similar across maturities. As shown in Figure 8, these findings imply that unconventional monetary policy shocks reduce all yields and shifts the yield curve downward through its impact on the market factor in all EMU countries ${ }^{21}$. Due to the bank based structure of the EA, unconventional policy measures included extensive liquidity provisions to the banking system. This policy aimed to increase the credit vol$\mathrm{um}^{22}$ and reduce the government bond returns by decreasing the risk of government bailouts and influencing agents' expectations for the future stance of the economy 23 . The impact on the market component of the bond yields is consistent with the objectives of these policies.

Our findings suggest that unconventional policies were effective in decreasing the common market component of the government bond returns. However, the absolute value of the loadings for factor 1 are higher for the core countries, which implies that the impact of policy shocks on the bond returns through the common market factor is stronger for the core countries. This heterogeneous response might be due to the structural differences in the two country groups. The impact of liquidity provision depends on how deep and solvent the banking sector is. Consequently, countries with more developed financial systems benefit more from the extensive liquidity provision. This pattern is consistent with Jäger and Grigoriadis (2017), which shows that the impact of long term liquidity financing operations and lowering the deposit rate to zero percent is negative and significant for the non-crisis EMU countries while they are insignificant for the crisis EMU countries.

-Figure 8 around here-

We obtain the impulse responses for the risk component of the bond yields by multiplying the

\footnotetext{
${ }^{21}$ Only for Portugal, the impact through the market factor is relatively higher at the long end of the yield curve, which causes a decline in the liquidity premium and makes the yield curve flatter.

${ }^{22}$ Darracq-Paries and De Santis (2015) show that the main transmission channel of LTROs is the credit provision by the banking sector.

${ }^{23}$ Gerlach et al. (2010) shows that bank related factors explain up to almost one percentage point of EA sovereign spreads. Fratzscher and Rieth (2015) finds that there is a bidirectional relationship between the sovereign risk and bank risk.
} 
impulse response function of factor 2 with its loadings. The risk factor increases in response to a normalized unconventional monetary policy shock. The loadings for factor 2 are negative for the periphery countries and positive for the core countries. Consequently, as shown in Figure 8b, unconventional policy shocks decrease the risk component of the bond returns in the periphery countries and increase them in the core countries through the risk factor. Our results also suggest that the impact on the risk component of the bond yields is persistent for the periphery countries. This pattern is consistent with Fratzscher and Rieth (2015), which shows that SMP decreases the sovereign spreads for the crisis EMU countries while it increases them for the non-crisis ones. One possible explanation for the pattern is that the risk on the ECB's balance sheet increases because of the purchase of risky country bonds which in turn affects the risk assessment of the core countries negatively and increases their bond returns. In other words, the risk in the periphery economies is shared by the core economies through ECB's asset purchases from the periphery economies.

To investigate whether the announcement of the SMP and OMT programs reduced the risk premium in the financially stressed countries, we also checked how the risk factor changed on the SMP and OMT announcement days. Table 3 shows that, on average, the risk factor increased by 10 basis points on the SMP and OMT announcement days which implies that these announcements reduced the sovereign spreads for Italy, Spain and Portugal. This finding suggests that the portfolio balance channel was effective in the sample period. It is also consistent with Falagiarda and Reitz (2015), Eser and Schwaab (2016), Chadha and Hantzsche (2018) and Fratzscher and Rieth (2015), which show that SMP reduced the EA risk by decreasing the sovereign spreads in the stressed EMU countries.

Finally, we multiply the impulse response function for factor 3 with its loadings to obtain the impulse responses for the term structure component of the bond yields. The term structure factor, also responds positively to unconventional policy shocks. However, the response of factor 3 is weaker than those of the other factors. As shown in Figure 8c, the loadings for factor 3 increase with the maturity for all countries except Portugal. Hence, uncoventional policy shocks make the yield curve slightly steeper in these countries. Only for Portugal, the term premiums for both medium and long term bonds decrease and the yield curve becomes flatter. Furthermore, since Portugal's factor loadings are negative and higher in absolute value for medium term bond returns, unconventional policy measures make the yield curve more convex. Overall, the impact is substantial for Portugal, and negligible for other countries.

\subsubsection{The overall impact on the EMU countries}

This section investigates the overall responses of the bond yields to monetary policy shocks. A nonstandard monetary policy shock which is equivalent to a 50 bps drop in EA 5-year yields induces

significant drops in yields for all maturities and countries. Expectedly, accommodative monetary 
shocks are priced rapidly in the bond market.

-Figure 9 around here-

Figure 9 shows the aggregate responses of selected bond yields to ECB's unconventional monetary policy announcements for 8 EMU countries 24 . The figure suggests that the identified policy announcements at the ZLB have been effective in easing financial conditions in both core and periphery EMU countries. The impact is substantial and persistent for the periphery while it is weaker and temporary for the core countries.

The results show that short-term, medium-term and long-term bond returns for Spain, Italy and Portugal decrease by around 150-200 basis points in response to a normalized unconventional monetary policy shock. Responses of the bond returns are persistent for all maturities. This pattern suggests that unconventional policy measures shift the yield curve downward permanently in the periphery countries.

The results for Germany, France, Austria, Netherlands and Belgium differ from those for the periphery countries. The previous section provided evidence that the policy shocks affect the bond returns in these countries negatively through the common market factor and positively through the risk factor. The cumulative responses show that the impact through the common market factor is stronger and the overall impact is negative. A normalized unconventional monetary policy shock reduces the bond returns by around 50 basis points in Germany, 90 basis points in France, Austria and Netherlands and 120 basis points in Belgium. The responses are weaker and transitory in these countries compared to those in the periphery countries. Consequently, the yield curve initially shifts downward and but later returns close to the initial level in 11 months for Belgium and 6 months for the other countries.

The results provide evidence that periphery countries benefited from the non-standard policies by the ECB more than the core countries did. The heterogeneity in the responses of the periphery and the core countries can be explained by the shifts in the sovereign risk as captured by factor 2. The sovereign bond spreads in Italy, Spain and Portugal increased relative to Germany due to the deterioration in the fiscal positions and macroeconomic fundamentals and concerns about the sustainability of government debt 25 . We find that unconventional policy measures and especially SMP and OMP announcements were effective in addressing these concerns and led to the convergence of the bond returns in the $\mathrm{EA}^{26}$.

We find that the impact of unconventional monetary policies is persistent, lasting longer than a year for the European periphery. This finding contrasts with the earlier studies which finds that the

\footnotetext{
${ }^{24}$ The impulse responses for individual maturities are reported in Appendix B.

${ }^{25}$ Gerlach et al. (2010), Arghyrou and Kontonikas (2012), De Grauwe and Ji (2013), De Santis (2012) and Giordano et al. (2013).

${ }^{26}$ The next section discusses the cross-country variation in more detail.
} 
impact dies within six months for the US, UK and EA (Wright (2012) and Rogers et al. (2014) ). Neely et al. (2014) argues that this transitory impact result in the earlier studies was driven by the instability of the structural VAR models caused by model mis-specification. Arguably, what allows our model to sidestep this problem and identify the persistent impact is the dimension reduction in the first step, which decreases the model uncertainty caused by omitted variables, unobservable factors and lagged endogeneity. Hence, when we test structural stability by using Bai and Perron's (2003) test based on the global information criterion, the procedure ${ }^{27}$ finds no breaks both in announcement and non-announcement day VARs of the factor model, and suggests that the model is stable and provides reliable forecasts for the overall impact and the persistence.

\subsubsection{The overall impact on the term structure of interest rates}

This section investigates the responses of the term-structure of the interest rates to the unconventional monetary policy shocks. The initial responses of the bond yields to expansionary announcements increase as the maturity increases approximately until 6-7 years, and then starts to decrease at the long-end of the yield curve. This pattern is in line with the aim of the unconventional policy measures. ECB, like other major central banks, mostly targets longer-term interest rates directly with UMP announcements. The evidence shows that the impact on the yields is the largest for mid-maturity bond returns: 2-3 years for Germany and Netherlands, 6-7 years for the other countries. Responses of these mid-maturity yields are more persistent than those of the shorter and longer maturities. These findings are consistent with the recent literature which studies the impact of UMP announcements on the bond yields. Bernhard and Ebner (2017) finds that the impact of expansionary shocks is larger for Swiss long-term government yields, in particular for bonds with maturities of 7 to 10 years. Rogers et al. (2014) finds that the impact of monetary policy shocks at the ZLB is larger at the long end of the yield curve for the US, UK and Japan. In contrast, Altavilla et al. (2016) and Eser and Schwaab (2016) show that SMP and OMT announcements cause a higher drop at the short end of the yield curve. However, these studies cover the period in which OMP and SMP programmes were announced and implemented. In this study, we are interested in the overall impact of policy announcements regardless of the specific programmes.

-Figure 10 around here-

Figure 10 shows the responses of the yield curves to a normalized monetary policy shock for each country. The solid black lines are the yield curves of the countries drawn using average bond yields over the period 2008-2016 for maturities up to 10 years. The dashed lines are estimated initial responses of the yields and responses after one week, one month, three months, six months and one year from the policy shock. The figure clearly shows that accommodative policy shocks diminish all yields considerably on the announcement day and shifts the yield curve downward for

\footnotetext{
${ }^{27}$ In this procedure, we utilize Schwarz information criterion and a heteroscedasticity and autocorrelation corrected standard errors. Considering the sample size of the announcement day VAR, we utilize $10 \%$ trimming for arranging the search region for structural breaks. Furthermore, we allow all coefficients of each equation in a VAR change simultaneously. This allows us to analyze equation by equation stability of the system.
} 
all countries. However, the impact is more persistent for the periphery countries, where it takes more than a year for the yields to return to the initial levels, compared to 6 months for the core economies. The monetary policy shock also decreases the curvature of yield curves in Portugal, Italy, Austria and France, whose mid-maturity yields react strongly.

\subsection{Cross-country variation in responses}

The preceding discussion provided evidence that the impact of the unconventional monetary policy shock on the bond yields is heterogeneous across the EMU countries. In this section, we investigate the relationship between the heterogeneity in the responses and country-specific characteristics and discuss the roles that different transmission channels might have played in this variation. We rely on simple correlations between the peak responses and observed country characteristics, and hence the results should be interpreted with caution 28 .

Figure 11 plots the peak responses of 10 -years yields against average proxies for country-specific characteristics and calculates simple cross-correlations. The dashed black line is the best-fit line for the relationship.

-Figure 11 around here-

Several patterns emerge from the figure. For one, it shows a negative relationship between peak responses of the yields and country-level index of financial stress. In other words, financial markets under stress benefit more from the expansionary announcements. This pattern is consistent with the argument that unconventional policy announcements reduced the uncertainty in the financial system and affected the economy through the uncertainty channel.

The figure also shows that higher peak responses are associated with low liquidity and dysfunctional financial markets. We use banks' liquid assets to deposits ratio to measure liquidity, and banks' non-performing loans to gross loans ratio and z-score to measure the dysfunction in the financial markets. This finding is consistent with the argument that unconventional policies improved liquidity conditions and market funtioning, and affected the economy through liquidity channel, as consistent with the evidence provided by Elbourne et al. (2018).

As for risk premium and duration risk, we find that the peak responses are higher at higher levels. We use debt to GDP ratio, risk premium on the sovereign bonds and credit ratings to measure the country risk premium and term spread to measure the duration risk. The positive relationship between these variables and peak responses are consistent with the argument that unconventional policy announcements reduced the sovereign and duration risks and affected the economy through

\footnotetext{
${ }^{28}$ The summary statistics and definitions for all of indicators are in Data Appendix Table B.3.
} 
international portfolio balance channel, as captured by the response of the risk structure factor ${ }^{29}$

Finally, the results show that the peak responses are higher in the countries with deeper financial markets and higher access to finance, proxied respectively by private credit to GDP ratio and bank branches per 100000 adults. This finding reflects the fact that the impact of liquidity provision to the financial system depends on how deep and solvent the banking sector is. Consequently, countries with deeper and more accessible banking sector benefited more from the extensive liquidity provision.

\section{Conclusion}

During the Great Recession, central banks in developed economies were forced to bring the interest rates down to zero, leaving no room for conventional policy. Consequently, the central banks experimented with several unconventional monetary policies, with little guidance from past experience. In the light of the recovery that followed, the common wisdom about these unconventional policies is that they were successful. There is, however, little consensus over the magnitude of their causal impact, and how the impact varied across countries, assets, and horizons.

This paper provides a comprehensive picture of the impact of unconventional monetary policies on government bond yields in European Monetary Union. What allows this in-depth treatment is a novel methodology that combines dynamic factor model, identification through heteroskedasticity and VAR. This methodology allows exploiting the unique structure of EMU with a single central bank and multiple economies, and estimating the impact of common unconventional policy shocks on 80 different bond yields. It also allows us to decompose the overall impact into the impacts on the market and risk components of the yields. Consequently, we are able to describe the impact of unconventional policies across different countries, maturities, yield components and time horizons.

The results corroborate that unconventional policies had a strong overall effect, but with significant variation across the countries. Broadly speaking, the policies decreased the risk component of the bond yields substantially for the periphery and increased them slightly for the core countries. This differential impact, consistent with the portfolio balance channel, drove the convergence in bond returns between the periphery and the core. The impact in the periphery was also more persistent than that in the core. As for maturities, we find that the impact worked on all, with a slightly bigger impact for mid-maturities. Finally, our results suggest that the impact was stronger for the countries which had higher financial distress and needed ECB's support the most and countries with developed markets where policies had room to operate.

${ }^{20}$ Chadha and Hantzsche (2018), Wieladek and Pascual (2016) and Bauer and Neely (2014) also find that portfoloio balance channel played an important role in the transmission of QE policies. 
The heterogeneity in the impact of unconventional monetary policies we document motivates further research into its drivers. From a theoretical perspective, the heterogeneity is of interest, as it provides insights about the relative importance of different transmission channels discussed in the literature under different conditions. From a policy perspective, understanding the heterogeneity matters, as it allows monetary authorities to design more effective interventions. While unconventional policies were introduced somewhat haphazardly during the crisis, they are now an important part of the monetary policy toolbox, and understanding how they interact with local economic structures is essential for using them effectively.

\section{References}

Altavilla, C., Brugnolini, L., Gürkaynak, R.S., Motto, R., Ragusa, G., 2019. Measuring euro area monetary policy. Working Paper Series 2281. European Central Bank.

Altavilla, C., Giannone, D., Lenza, M., 2016. The Financial and Macroeconomic Effects of the OMT Announcements. International Journal of Central Banking 12, 29-57.

Arghyrou, M.G., Kontonikas, A., 2012. The EMU sovereign-debt crisis: Fundamentals, expectations and contagion. Journal of International Financial Markets, Institutions and Money 22, 658-677. doi:10.1016/j.intfin.2011.10.

Bai, J., Ng, S., 2013. Principal components estimation and identification of static factors. Journal of Econometrics 176, 18-29.

Bai, J., Perron, P., 2003. Computation and analysis of multiple structural change models. Journal of applied econometrics 18, 1-22.

Bauer, M.D., Neely, C.J., 2014. International channels of the fed's unconventional monetary policy. Journal of International Money and Finance 44, $24-46$.

Bernhard, S., Ebner, T., 2017. Cross-border spillover effects of unconventional monetary policies on Swiss asset prices. Journal of International Money and Finance 75, 109-127. doi:10.1016/j . jimonfin.2017.0.

Box, G.E., 1949. A general distribution theory for a class of likelihood criteria. Biometrika 36, 317-346.

Buch, C.M., Bussiere, M., Goldberg, L., Hills, R., 2018. The International Transmission of Monetary Policy. Working Paper 24454. National Bureau of Economic Research. doi:10.3386/w24454.

Cecioni, M., Ferrero, G., Secchi, A., 2011. Unconventional monetary policy in theory and in practice 
Chadha, S.J., Hantzsche, A., 2018. The impact of the ECB's QE programme: core versus periphery. Working Papers. NIESR Discussion Paper.

Chen, Q., Filardo, A., He, D., Zhu, F., 2012. International spillovers of central bank balance sheet policies, in: for International Settlements, B. (Ed.), Are central bank balance sheets in Asia too large?. Bank for International Settlements. volume 66 of BIS Papers chapters, pp. 220-264. URL: https://ideas.repec.org/h/bis/bisbpc/66-16.html.

Darracq-Paries, M., De Santis, R.A., 2015. A non-standard monetary policy shock: The ECB's 3-year LTROs and the shift in credit supply. Journal of International Money and Finance 54, 1-34. doi:10.1016/j.jimonfin.2015.0.

De Grauwe, P., Ji, Y., 2013. Self-fulfilling crises in the Eurozone: An empirical test. Journal of International Money and Finance 34, 15-36. doi:10.1016/j.jimonfin.2012.1.

De Santis, R.A., 2012. The Euro area sovereign debt crisis: safe haven, credit rating agencies and the spread of the fever from Greece, Ireland and Portugal. Working Paper Series 1419. European Central Bank.

Elbourne, A., Ji, K., Duijndam, S., 2018. The effects of unconventional monetary policy in the euro area. CPB Discussion Paper 371. CPB Netherlands Bureau for Economic Policy Analysis.

Eser, F., Schwaab, B., 2016. Evaluating the impact of unconventional monetary policy measures: Empirical evidence from the ECB's Securities Markets Programme. Journal of Financial Economics $119,147-167$. doi:10.1016/j.jfineco.2015.08

Falagiarda, M., Reitz, S., 2015. Announcements of ECB unconventional programs: Implications for the sovereign spreads of stressed euro area countries. Journal of International Money and Finance 53, 276-295.

Fratzscher, M., Duca, M.L., Straub, R., 2016. ECB Unconventional Monetary Policy: Market Impact and International Spillovers. IMF Economic Review 64, 36-74.

Fratzscher, M., Rieth, M., 2015. Monetary policy, bank bailouts and the sovereign-bank risk nexus in the euro area. CEPR Discussion Papers 10370. C.E.P.R. Discussion Papers.

Gagnon, J., Raskin, M., Remache, J., Sack, B., 2011. The Financial Market Effects of the Federal Reserve's Large-Scale Asset Purchases. International Journal of Central Banking 7, 3-43.

Ángel García, J., Gimeno, R., 2014. Flight-to-liquidity flows in the euro area sovereign debt crisis. Working Papers 1429. Banco de España;Working Papers Homepage.

Gerlach, S., Schulz, A., Wolff, G.B., 2010. Banking and Sovereign Risk in the Euro Area. CEPR Discussion Papers 7833. C.E.P.R. Discussion Papers. 
Gertler, M., Karadi, P., 2011. A model of unconventional monetary policy. Journal of Monetary Economics 58, 17-34.

Giordano, R., Pericoli, M., Tommasino, P., 2013. Pure or Wake-up-Call Contagion? Another Look at the EMU Sovereign Debt Crisis. International Finance 16, 131-160.

Glick, R., Leduc, S., 2012. Central bank announcements of asset purchases and the impact on global financial and commodity markets. Journal of International Money and Finance 31, 2078-2101. doi:10.1016/j.jimonfin.2011.0.

Gräb, J., Żochowski, D., 2017. The international bank lending channel of unconventional monetary policy. Working Paper Series 2109. European Central Bank.

Haldane, A., Roberts-Sklar, M., Wieladek, T., Young, C., 2016. QE: The Story so far. Bank of England working papers 624. Bank of England.

Hamilton, J.D., Wu, J.C., 2012. The Effectiveness of Alternative Monetary Policy Tools in a Zero Lower Bound Environment. Journal of Money, Credit and Banking 44, 3-46. doi j.1538-4616. $2011.00476 . x$.

IMF, 2013. Unconventional Monetary Policies - Recent Experiences and Prospect. IMF Policy Paper. International Monetary Fund.

Jäger, J., Grigoriadis, T., 2017. The effectiveness of the ECB's unconventional monetary policy: Comparative evidence from crisis and non-crisis Euro-area countries. Journal of International Money and Finance 78, 21-43. doi $10.1016 / \mathrm{j} \cdot \mathrm{jimonfin} .2017 .0$.

Joyce, M., Miles, D., Scott, A., Vayanos, D., 2012. Quantitative easing and unconventional monetary policy-an introduction. The Economic Journal 122, F271-F288.

Joyce, M.A.S., Lasaosa, A., Stevens, I., Tong, M., 2011. The Financial Market Impact of Quantitative Easing in the United Kingdom. International Journal of Central Banking 7, 113-161.

Kashyap, A.K., Stein, J.C., 2000. What do a million observations on banks say about the transmission of monetary policy? American Economic Review 90, 407-428. doi:10.1257/aer.90.3.407.

Kilian, L., 1998. Small-sample confidence intervals for impulse response functions. The Review of Economics and Statistics 80, 218-230.

Krishnamurthy, A., Vissing-Jorgensen, A., 2011. The Effects of Quantitative Easing on Interest Rates: Channels and Implications for Policy. NBER Working Papers 17555. National Bureau of Economic Research, Inc.

Martin, C., Milas, C., 2012. Quantitative easing: a sceptical survey. Oxford Review of Economic Policy 28, 750-764. 
McCracken, M.W., Ng, S., 2016. FRED-MD: A Monthly Database for Macroeconomic Research. Journal of Business \& Economic Statistics 34, 574-589. doi:10.1080/07350015.2015.106.

Neely, C.J., et al., 2014. How persistent are unconventional monetary policy effects? Federal Reserve Bank of St. Louis Working Paper Series .

Politis, D.N., Romano, J.P., 1994. The stationary bootstrap. Journal of the American Statistical association 89, 1303-1313.

Rigobon, R., Sack, B., 2003. Measuring the reaction of monetary policy to the stock market. The Quarterly Journal of Economics 118, 639-669.

Rogers, J.H., Scotti, C., Wright, J.H., 2014. Evaluating asset-market effects of unconventional monetary policy: a multi-country review. Economic Policy 29, 749-799.

Stock, J.H., Watson, M.W., 2002. Forecasting using principal components from a large number of predictors. Journal of the American statistical association 97, 1167-1179.

Vayanos, D., Vila, J.L., 2009. A Preferred-Habitat Model of the Term Structure of Interest Rates. NBER Working Papers 15487. National Bureau of Economic Research, Inc.

Wieladek, T., Pascual, A.I.G., 2016. The European Central Bank's QE: A New Hope. CESifo Working Paper Series 5946. CESifo Group Munich.

Woodford, M., 2012. Methods of policy accommodation at the interest-rate lower bound. Proceedings - Economic Policy Symposium - Jackson Hole , 185-288URL: https://ideas.repec.org/ a/fip/fedkpr/y2012p185-288.html.

Wright, J.H., 2012. What does monetary policy do to long-term interest rates at the zero lower bound? The Economic Journal 122, F447-F466. 


\section{Tables and figures}

Table 1: Change in 10-year Sovereign Yields Summary Statistics

\begin{tabular}{|c|c|c|c|c|c|c|c|c|}
\hline Country & $\underline{\text { Mean }}$ & St. Dev. & $\underline{\operatorname{Min}}$ & $\underline{\text { Date }}$ & $\underline{\operatorname{Max}}$ & Date & Kurtosis & Skew. \\
\hline \multicolumn{9}{|c|}{ Difference on Policy Dates } \\
\hline Austria & -0.003 & 0.060 & -0.164 & $30-N o v-11$ & 0.170 & 03-Jun-15 & 3.600 & 0.118 \\
\hline Belgium & -0.014 & 0.071 & -0.429 & 30-Nov-11 & 0.203 & 03-Dec-15 & 10.724 & -1.319 \\
\hline France & -0.007 & 0.060 & -0.203 & 30-Nov-11 & 0.189 & 03-Dec-15 & 4.112 & 0.159 \\
\hline Germany & -0.002 & 0.064 & -0.181 & 19-Mar-09 & 0.196 & 03-Dec-15 & 3.876 & 0.308 \\
\hline Italy & -0.011 & 0.109 & -0.811 & 08-Aug-11 & 0.359 & 02-Aug-12 & 21.391 & -2.188 \\
\hline Netherlands & -0.004 & 0.059 & -0.159 & 06-Nov-08 & 0.174 & 03-Dec-15 & 3.334 & 0.100 \\
\hline Portugal & -0.030 & 0.239 & -2.042 & 10-May-10 & 0.629 & 07-Jul-11 & 35.595 & -4.231 \\
\hline Spain & -0.011 & 0.129 & -0.905 & 08-Aug-11 & 0.510 & 02-Aug-12 & 19.372 & -1.525 \\
\hline \multicolumn{9}{|c|}{ Difference on Non-Policy Dates } \\
\hline Austria & -0.002 & 0.051 & -0.266 & 01-Dec-11 & 0.352 & 03-Jan-12 & 7.548 & 0.569 \\
\hline Belgium & -0.001 & 0.054 & -0.274 & 05-Dec-11 & 0.371 & 25-Nov-11 & 8.401 & 0.708 \\
\hline France & -0.001 & 0.048 & -0.216 & 24-May-12 & 0.247 & 10-Nov-11 & 5.085 & 0.213 \\
\hline Germany & -0.002 & 0.050 & -0.193 & 02-Nov-11 & 0.238 & $25-\mathrm{Nov}-11$ & 4.323 & 0.165 \\
\hline Italy & 0.000 & 0.074 & -0.445 & 11-Nov-11 & 0.579 & 09-Nov-11 & 10.613 & 0.338 \\
\hline Netherlands & -0.002 & 0.047 & -0.180 & 02-Nov-11 & 0.278 & 09-Dec-08 & 4.731 & 0.309 \\
\hline Portugal & 0.002 & 0.223 & -1.521 & 31-Jan-12 & 3.174 & $25-N o v-11$ & 72.465 & 3.992 \\
\hline Spain & 0.000 & 0.079 & -0.540 & 27-Jan-12 & 0.600 & 20-Jan-12 & 10.972 & -0.097 \\
\hline
\end{tabular}


Table 2: Factors Estimated: Total Variation Explained, 0.70

\begin{tabular}{llllll}
\hline$m R^{2}(1)$ & 0.451 & $m R^{2}(2)$ & 0.191 & $m R^{2}(3)$ & 0.050 \\
\hline gb6y_Fra & 0.815 & gb5y_Ita & 0.592 & gb4y_Por & 0.646 \\
gb7y_Fra & 0.810 & gb4y_Ita & 0.585 & gb6y_Por & 0.615 \\
gb8y_Fra & 0.794 & gb8y_Ita & 0.584 & gb5y_Por & 0.614 \\
gb9y_Fra & 0.782 & gb7y_Ita & 0.573 & gb3y_Por & 0.579 \\
gb10y_Fra & 0.765 & gb7y_Spa & 0.573 & gb10y_Por & 0.534 \\
gb5y_Fra & 0.740 & gb6y_Ita & 0.572 & gb2y_Por & 0.442 \\
gb7y_Aus & 0.737 & gb6y_Spa & 0.567 & gb30y_Spa & 0.038 \\
gb10y_Aus & 0.712 & gb5y_Spa & 0.565 & gb30y_Ita & 0.028 \\
gb6y_Net & 0.709 & gb4y_Spa & 0.559 & gb2y_Ger & 0.028 \\
gb4y_Net & 0.704 & gb8y_Spa & 0.547 & gb9y_Spa & 0.025 \\
gb6y_Aus & 0.696 & gb3y_Spa & 0.547 & gb10y_Spa & 0.025 \\
gb8y_Net & 0.695 & gb9y_Ita & 0.537 & gb10y_Ita & 0.025 \\
gb5y_Net & 0.689 & gb9y_Spa & 0.535 & gb3y_Ger & 0.022 \\
gb9y_Net & 0.686 & gb10y_Ita & 0.531 & gb1y_Ger & 0.017 \\
gb9y_Bel & 0.683 & gb10y_Spa & 0.512 & gb30y_Fra & 0.017 \\
\hline
\end{tabular}

Note: This table lists the 15 series that load most heavily on the first 3 factors along with $R^{2}$ in a regression of the series on the factor. For example, factor 1 explains 0.451 variation of 80 series. First factor explains 0.815 of the variation in 6 -year French yields, 0.712 of the variation of 7-year Australian yields.

Table 3: Changes in the Factor 2 on SMP and OMT Days

\begin{tabular}{lcc}
\hline & Mean & St. Dev. \\
\cline { 2 - 3 } Factor 2 (level) \\
Policy days & -10.197 & 6.672 \\
Non-policy days & -4.799 & 6.752 \\
Factor 2 (daily change) \\
Policy days & 1.408 & 1.955 \\
Non-policy days & -0.003 & 0.427 \\
\hline
\end{tabular}

Note: Policy days contain only SMP and OMT announcement days. 


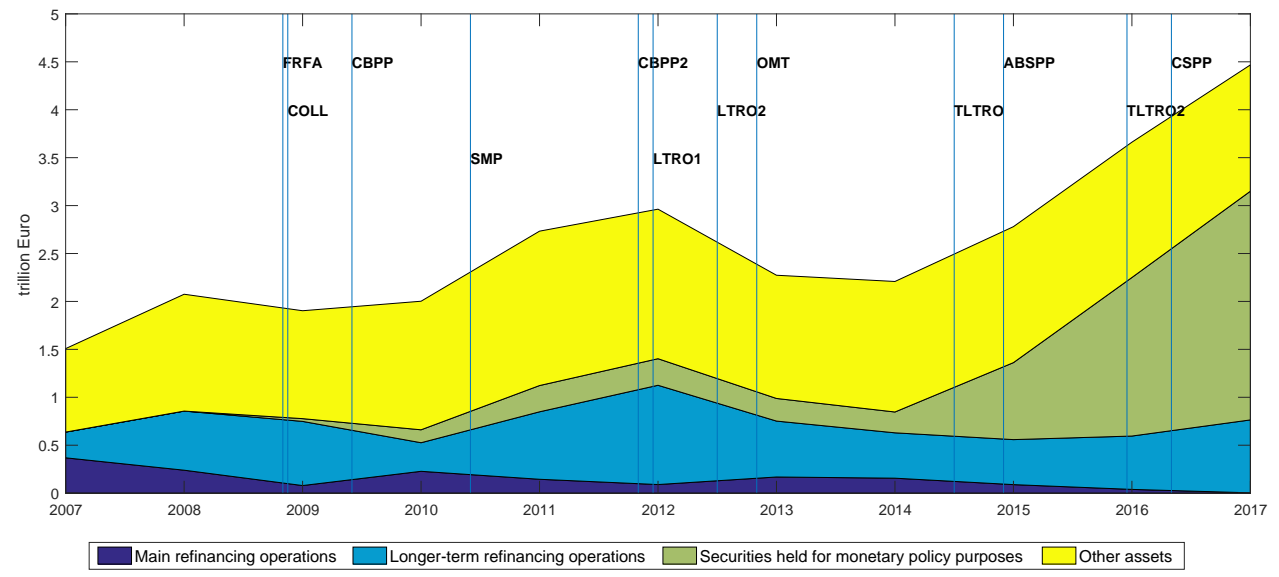

Figure 1: ECB Balance Sheet

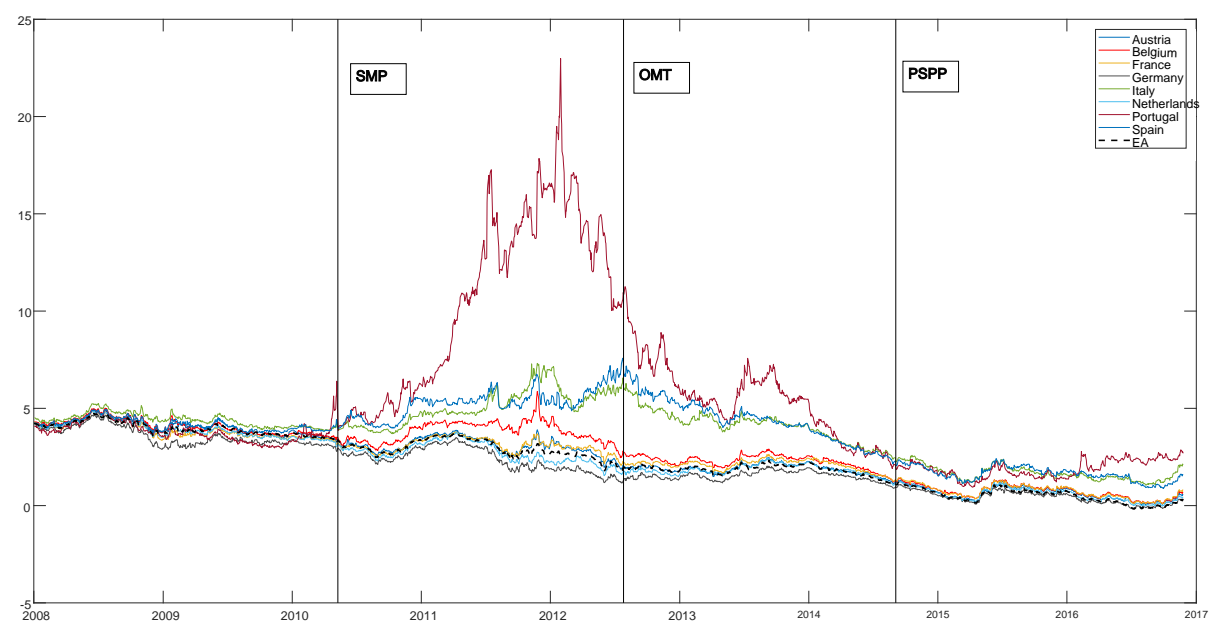

Figure 2: 10-year Bond Yields 


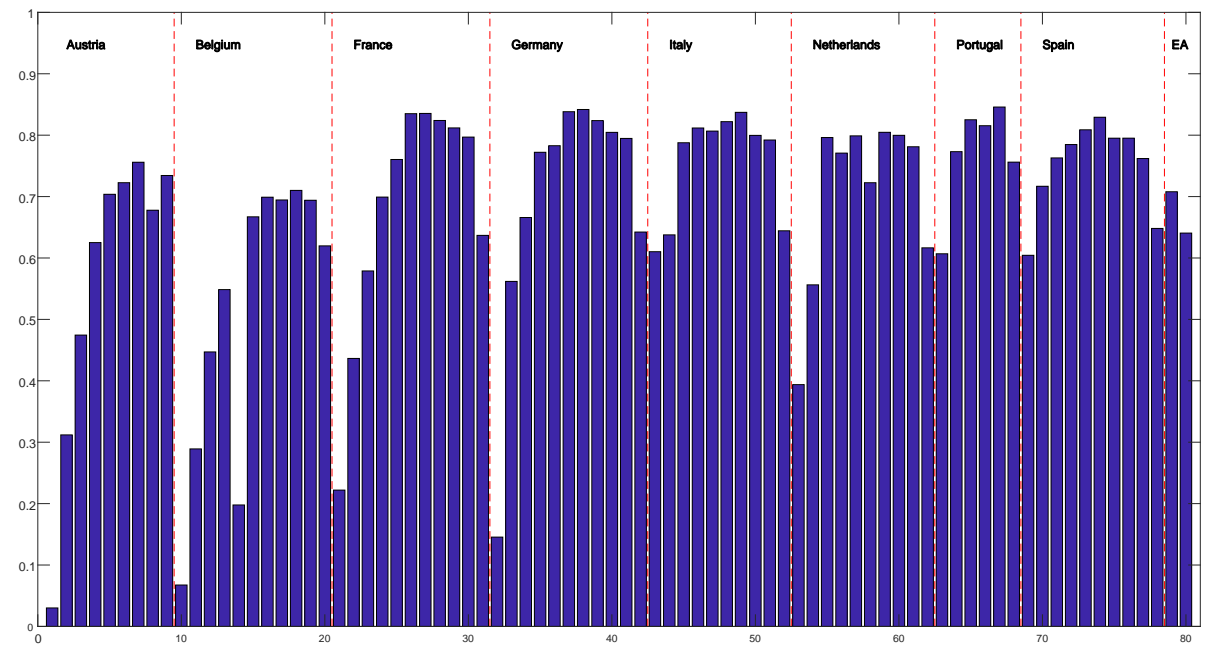

Figure 3: Model Fit and $R^{2}$
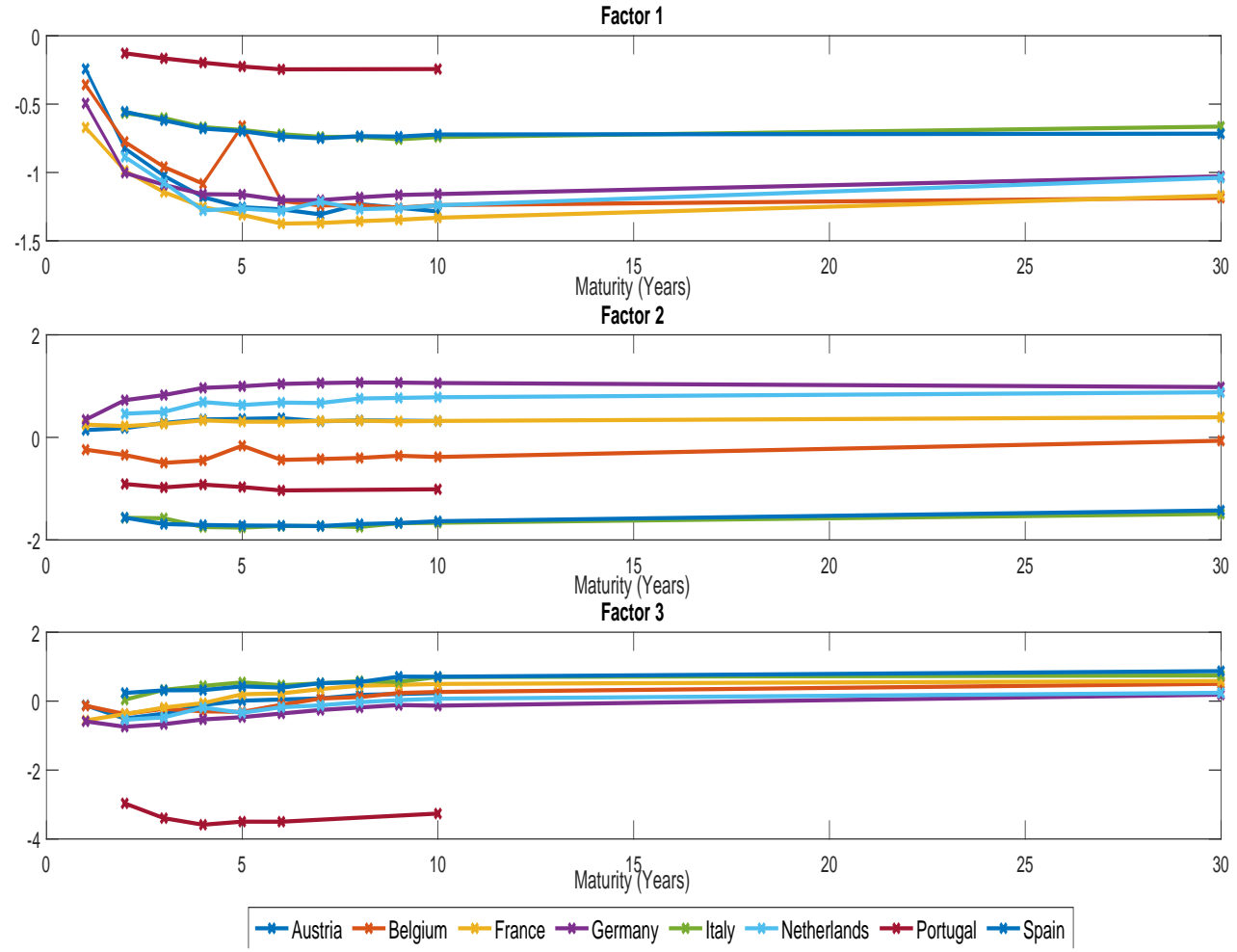

Figure 4: Factors Loadings 


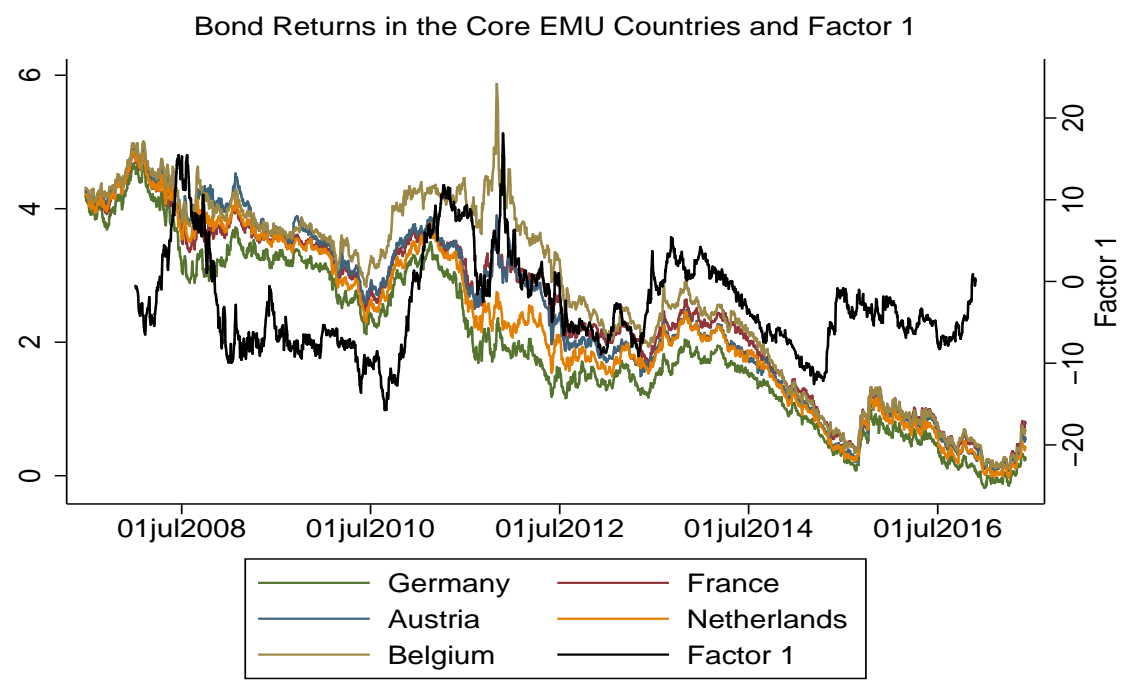

(a) Factor 1

Risk Premium of 5-Year Bond Returns in Periphery EMU Countries and Factor 2

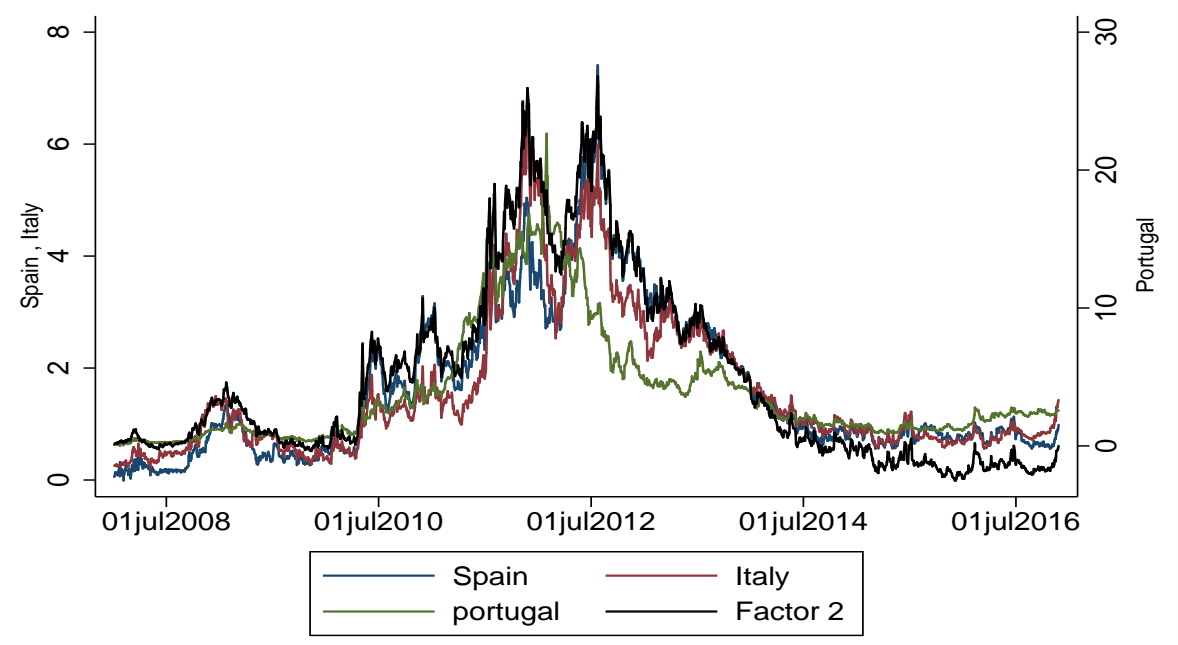

(b) Factor 2

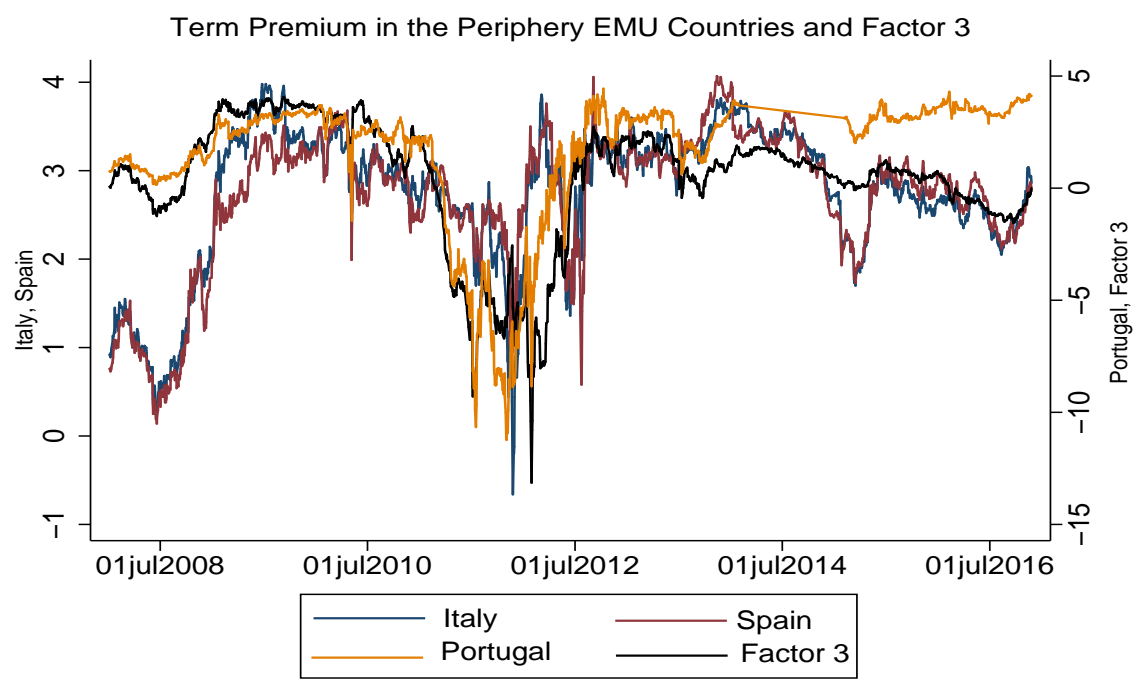

29

(c) Factor 3

Figure 5: Factors and Related Economic Variables 

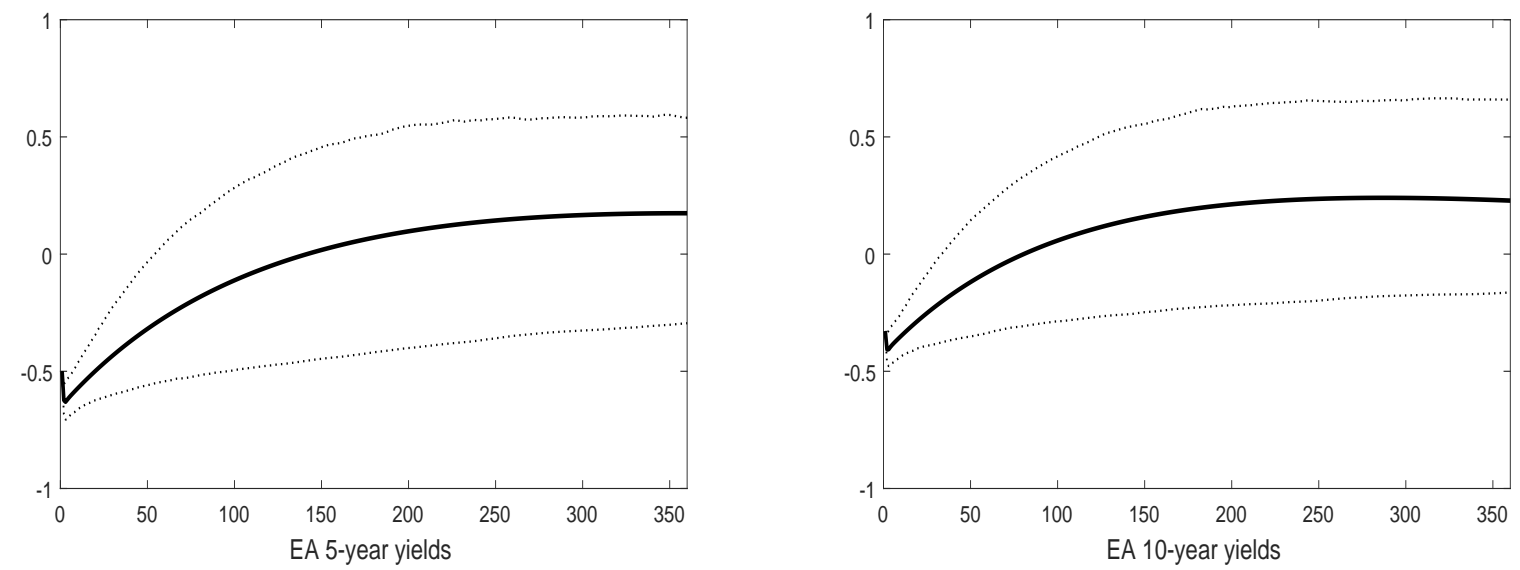

Figure 6: Impulse Responses of Bond Yields of EA
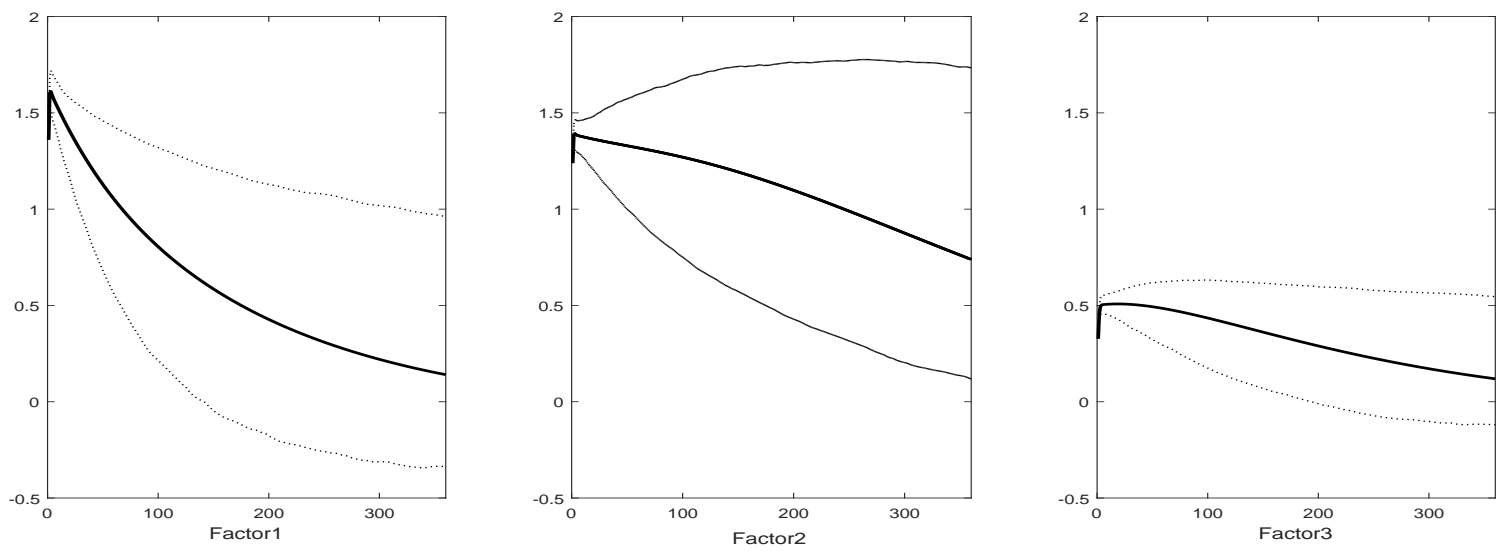

Figure 7: Impulse Responses of the Estimated Factors 

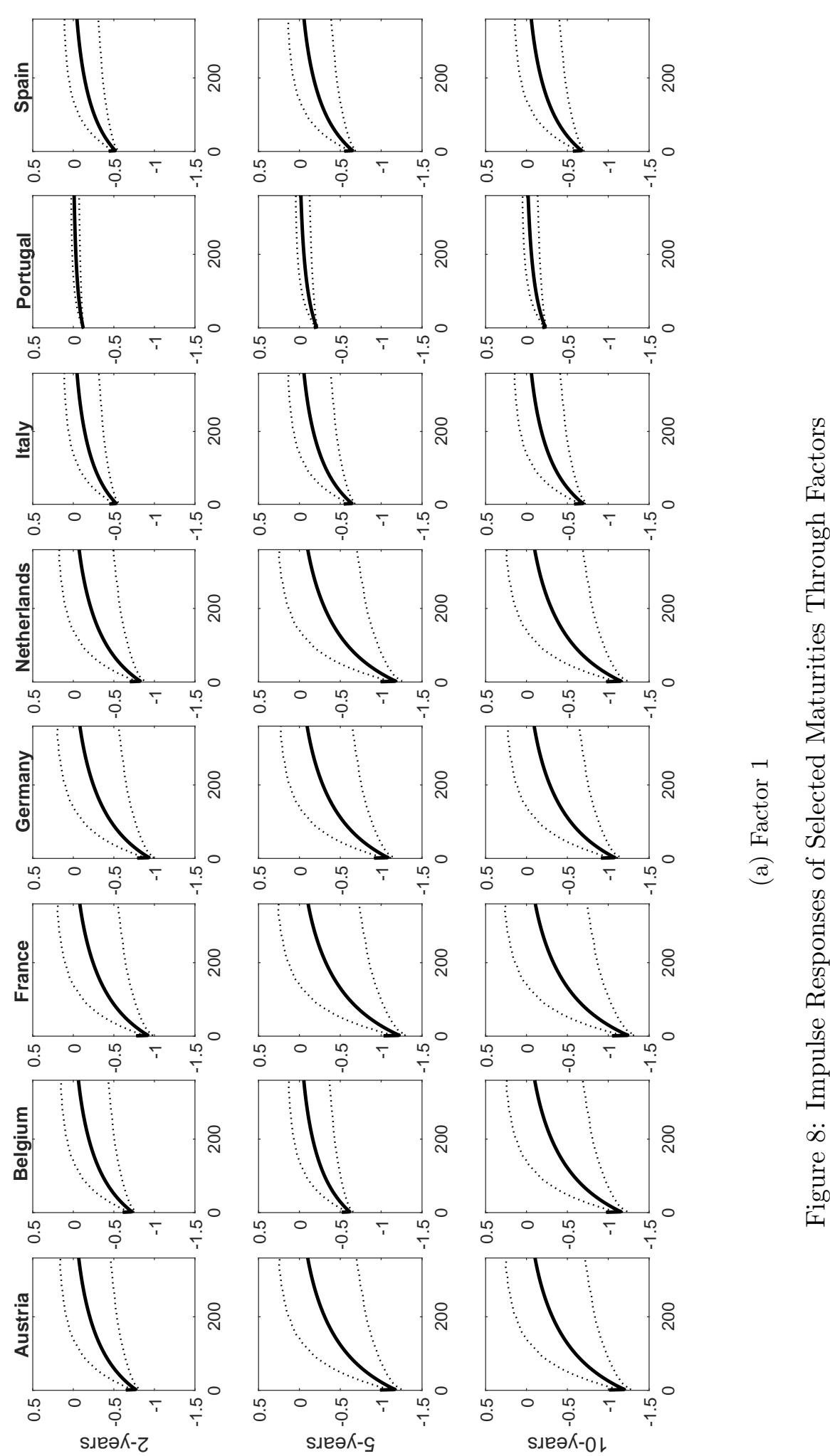

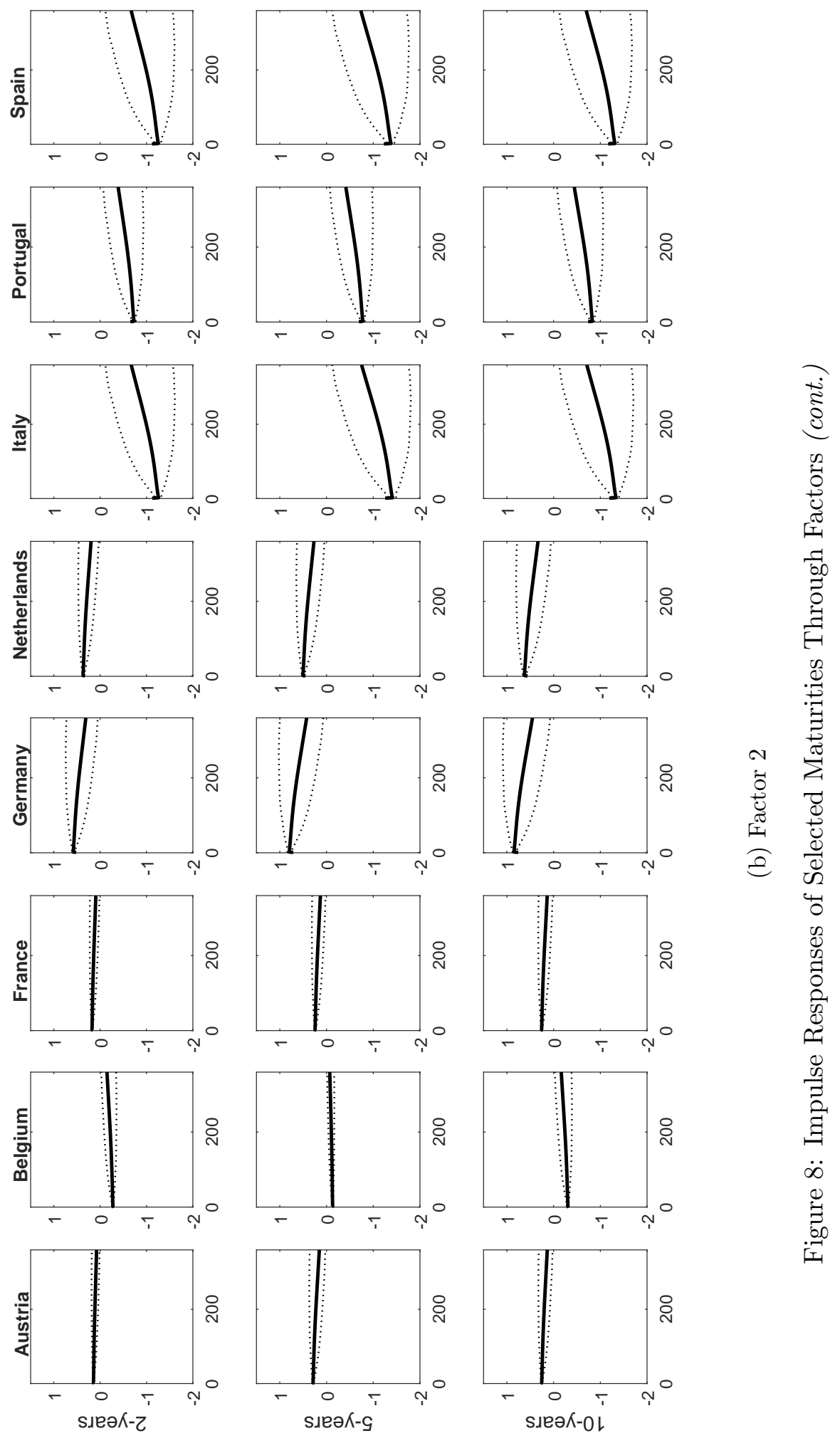

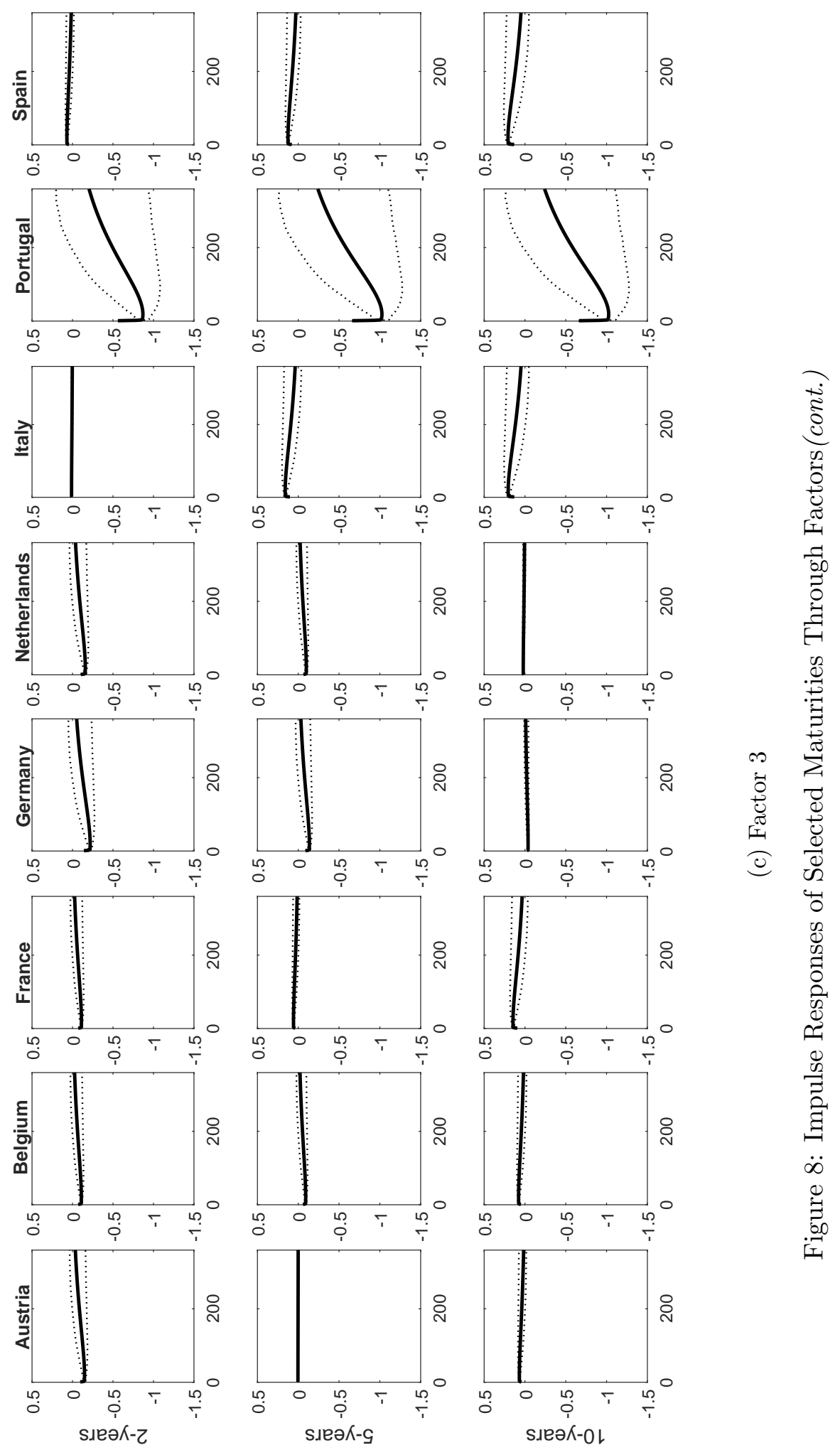

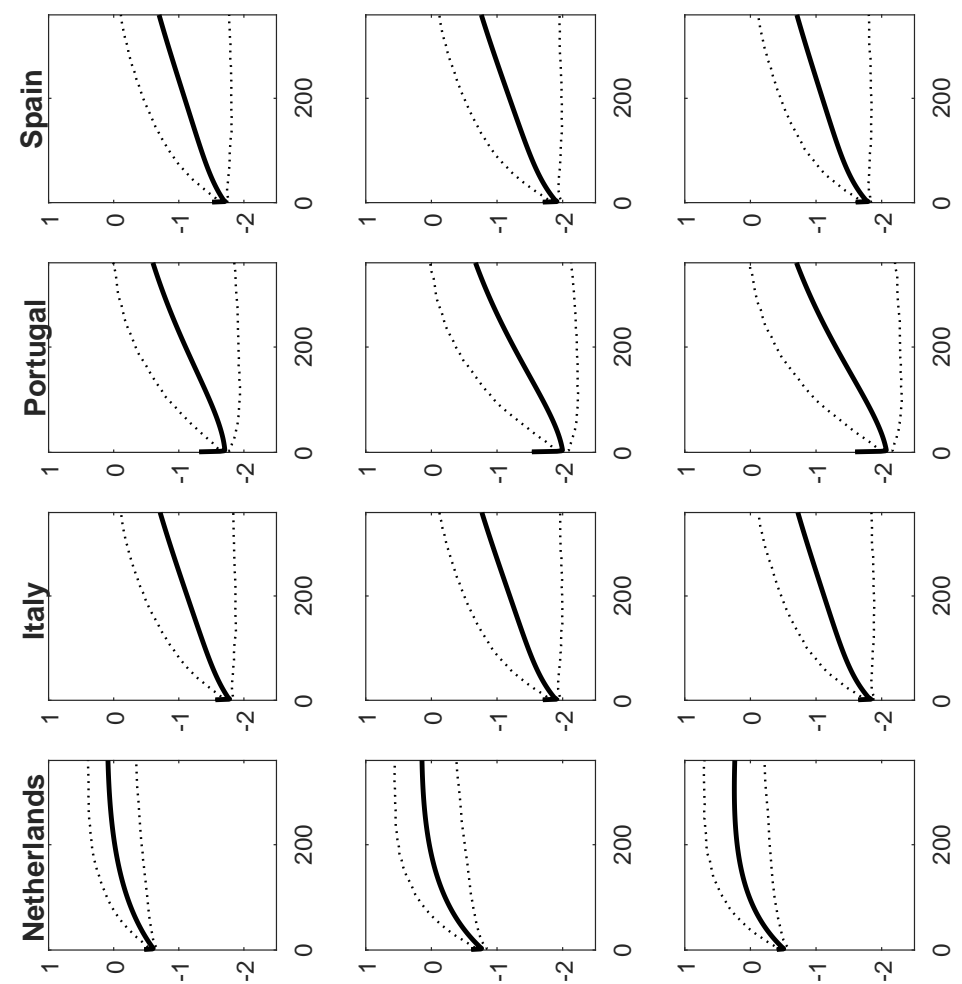

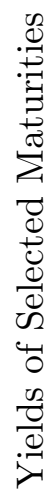
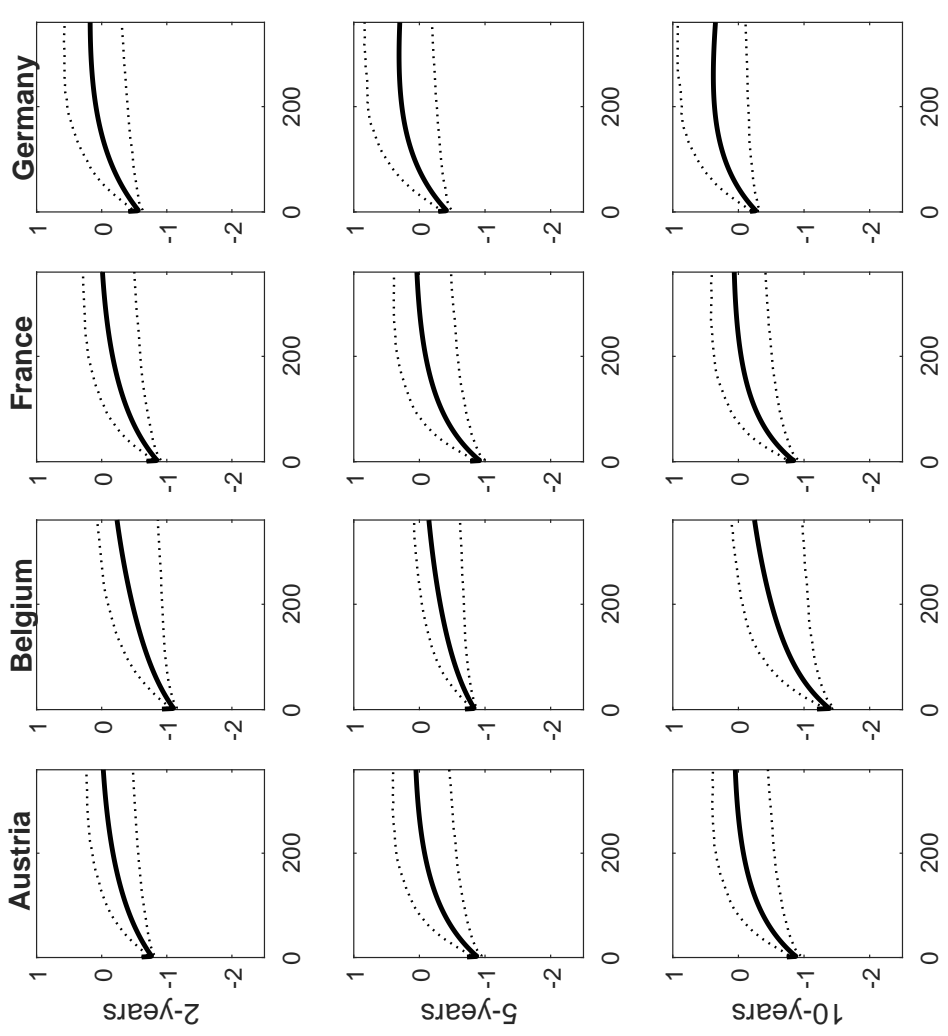

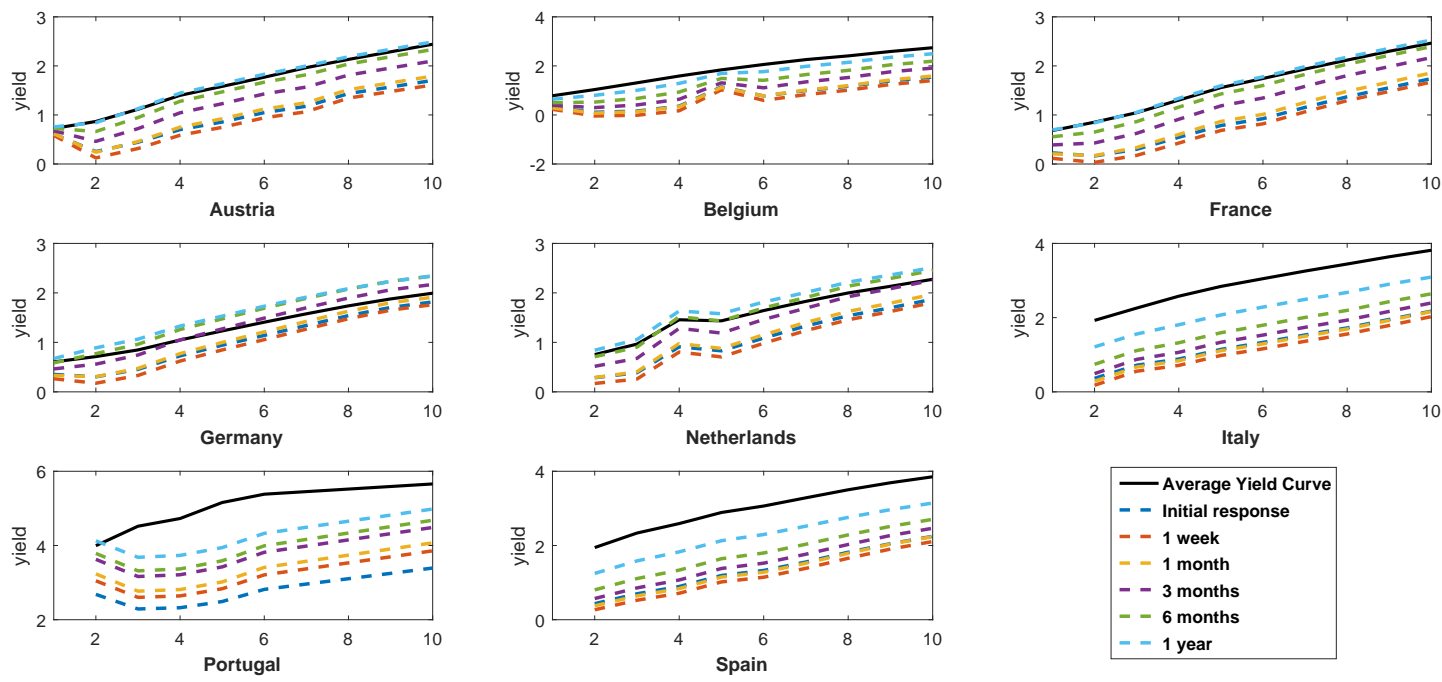

\begin{tabular}{l}
\hline- Average Yield Curve \\
-- Initial response \\
--1 week \\
--1 month \\
--3 months \\
--6 months \\
--1 year
\end{tabular}

Figure 10: The Impact of UMP on Term Structure of Yield Curve
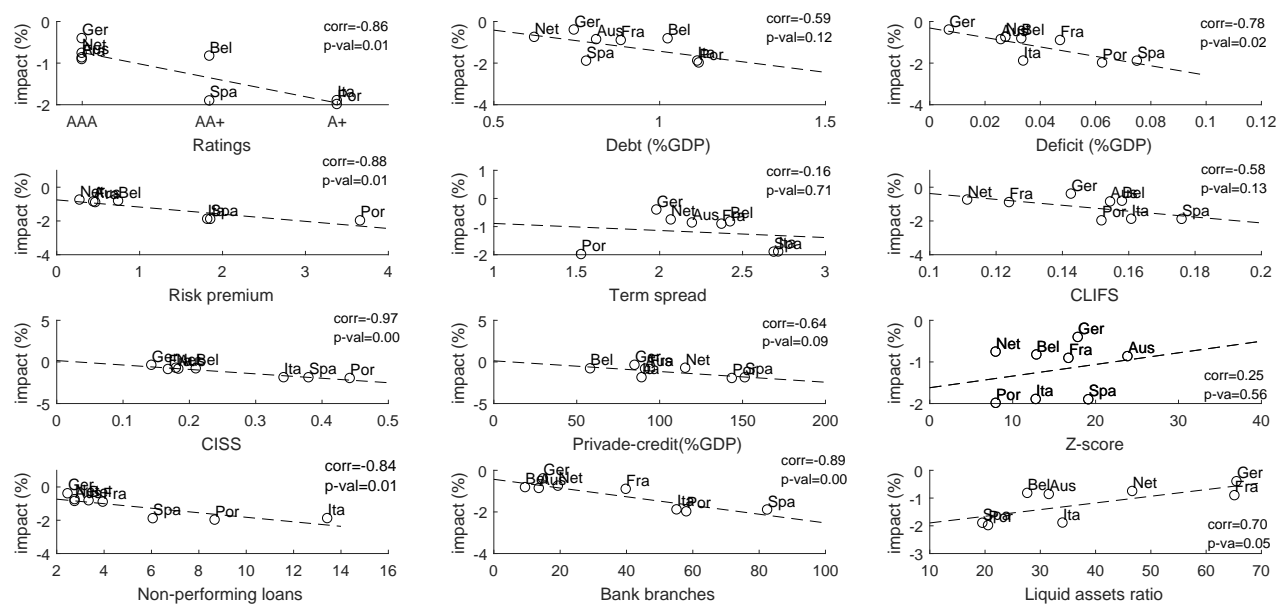

Figure 11: Cross-correlations Between Estimated Responses and Country-specific Proxies 


\section{A Bootstrap confidence interval}

In order to find the bootstrapped confidence interval for the IRFs, we use the following routine:

1. First we pick the number of bootstrap replication, $B$, and the significance level as $\alpha$.

2. We extract $\mathrm{r}$ factors, $\hat{F}_{t}$, from $Y_{t}$ and also save the factor loadings $\Lambda$. Then, we estimate the full sample VAR using $\hat{F}_{t}$ and get the reduced form residuals $\hat{\epsilon}_{t}$ and the OLS coefficients $\hat{\Phi}(L)$.

3. For $b=1,2, \ldots, B$, we draw a random sample of the indices from the set $\{1,2, \cdots, T\}$ according to stationary bootstrap of Politis and Romano (1994) with 10 days of average block length. We denote the resampled set of the indices as $\left\{U_{t}^{*(b)}\right\}_{t=1}^{T}$. The resampled residuals are generated as $\hat{\epsilon}_{t}^{*(b)}=\hat{\epsilon}_{U_{t}^{*(b)}}$.

4. While resampling the residuals, we also resample $p_{t}$. This leads to a change in the announcement date vector, say $\operatorname{pol}_{t}^{*(b)}=\operatorname{pol}_{U_{t}^{*(b)}}$.

5. Then, we reconstruct the factors $\hat{F}_{t}$ by using the resampled residuals and the VAR coefficients $\hat{\Phi}(L)$ from the full sample VAR:

$$
\hat{F}_{t}^{*(b)}=\hat{\Phi}(L) \hat{\epsilon}_{t}^{*(b)}
$$

6. Now applying the heteroscedasticity based identification method to $\hat{F}_{t}^{*(b)}$, we obtain the bootstrap estimates $\hat{\Sigma}_{0}^{*(b)}, \hat{\Sigma}_{1}^{*(b)}, \hat{V}_{0}^{*(b)}, \hat{V}_{1}^{*(b)}$ and $\hat{R}_{1}^{*(b)} 30$. Note that for the announcement days we use $\operatorname{pol}_{t}^{*(b)}$ instead of pol $_{t}$.

7. We also run a full sample VAR with the resampled $\hat{F}_{t}^{*(b)}$ to get VAR coefficients estimates $\hat{F}^{*(b)}(L)$. We apply the Kilian's $(1998)$ bias adjustment procedure for these coefficients. By using these bootstrap parameter estimates $\hat{R}_{1}^{*(b)}$ and $\hat{\Phi}(L)^{*(b)}$ we obtain the bootstrapped IRF, say $I R F_{h}^{*(b)}$ for the horizon $h$. Then, we obtain the bootstrap replicate of the observed variables as $\widetilde{I R F}_{h}^{*(b)}=\Lambda^{\prime} I R F_{h}^{*(b)}$ for $b=1,2, \cdots, B$.

8. Repeating the steps 3-7 B times, finally we have a bootstrap distribution for IRF, $\left\{\widetilde{I R F}_{h}^{*(b)}\right\}_{b=1}^{B}$. We can extract the confidence bands for the IRF by finding $\alpha / 2^{\text {th }}$ and $(1-\alpha / 2)^{\text {th }}$ quantiles of the bootstrap distribution.

We apply the bootstrapped Box $\mathrm{m}$ test for the factor model. The bootstrapping procedure is as follows:

\footnotetext{
${ }^{30}$ One can skip the estimation of $R_{1}$ for the bootstrap replication, since the estimation of $R_{1}$ can cause additional variance that can widen the confidence interval.
} 
1. First we pick the number of the bootstrap replication, $B$, and the significance level $\alpha$.

2. We estimate the full sample VAR for the factor model and obtain the reduced form residuals $\hat{\epsilon}_{t}$ and the OLS coefficients $\hat{\Phi}(L)$.

3. For $b=1,2, . ., B$, we resample the residuals $\hat{\epsilon}_{t}$ according to standard iid bootstrap method 31 The resampled residuals are denoted as $\hat{\epsilon}_{t}^{*(b)}$.

4. This time we do not track the new index of residuals which corresponds to policy days, since under the null hypothesis residuals for both regimes are generated from same distribution .

5. Then, we reconstruct the observable variables $\hat{F}_{t}$ by using resampled residuals and the VAR coefficients from full sample VAR:

$$
\hat{F}_{t}^{*(b)}=\hat{\Phi}(L) \hat{\epsilon}_{t}^{*(b)}
$$

6. Now applying the heteroscedasticity based identification method to $\hat{F}_{t}^{*(b)}$, we obtain bootstrap estimates $\hat{\Sigma}_{0}^{*(b)}$ and $\hat{\Sigma}_{1}^{*(b)}$. Use same policy day dummy pol .

7. Using these bootstrapped estimates, we construct the test statistic $B M^{*(b)}$.

8. Repeating the steps 3-7 $B$ times, we have a bootstrap distribution for the test statistic $B M$, say $\left\{B M^{*(b)}\right\}_{b=1}^{B}$. We can apply standard bootstrap inference.

\section{B Additional tables and figures}

Table B.1: ECB Monetary Policy Announcements

\begin{tabular}{|c|c|}
\hline Announcement date & Announcement description \\
\hline 10-Jan-08 & ECB decided to conduct US dollar liquidity providing operations \\
\hline 7-Feb-08 & ECB decided to renew two outstanding supplementary longer term refinancing operations \\
\hline 11-Mar-08 & ECB decided to conduct US dollar liquidity providing operations \\
\hline 28-Mar-08 & ECB decided to conduct supplementary longer term refinancing operations \\
\hline 2-May-08 & ECB decided to enhance US dollar liquidity providing operations \\
\hline 30-Jul-08 & ECB decided to enhance US dollar liquidity providing operations \\
\hline 31-Jul-08 & ECB decided to renew two outstanding supplementary longer term refinancing operations \\
\hline 4-Sep-08 & ECB decided to renew three outstanding supplementary longer term refinancing operations \\
\hline 18-Sep-08 & ECB decided to enhance US dollar liquidity providing operations \\
\hline 26-Sep-08 & ECB decided to enhance US dollar liquidity providing operations \\
\hline 29-Sep-08 & ECB decided to double the temporary swap lines \\
\hline 7-Oct-08 & $\begin{array}{l}\text { ECB decided to enhance longer term refinancing operations and expand US dollar providing liquidity oper- } \\
\text { ations }\end{array}$ \\
\hline 8-Oct-08 & ECB decided to adopt a fixed rate tender with full allotment \\
\hline 13-Oct-08 & ECB decided to enhance US dollar liquidity providing operations \\
\hline $15-O c t-08$ & $\begin{array}{l}\text { ECB decided to expand the list of assets eligible as collateral, enhance the provision of longer term refinancing } \\
\text { operations, and provide US dollar liquidity through foreign exchange swaps }\end{array}$ \\
\hline
\end{tabular}

\footnotetext{
${ }^{31}$ One can use stationary bootstrap of Politis and Romano (1994)
} 
Continuation of Table B.1

\begin{tabular}{|c|c|}
\hline Announcement date & Announcement description \\
\hline 18-Dec-08 & $\begin{array}{l}\text { ECB decided that the main refinancing operations will continue to be carried out theroug a fixed rate tender } \\
\text { procedure with full allotment as long as needed }\end{array}$ \\
\hline 19-Dec-08 & ECB decided to continue US dollar liquidity providing operations \\
\hline 3-Feb-09 & ECB decided to extend liquidity swap arrangements with the FED \\
\hline 5-Mar-09 & $\begin{array}{l}\text { ECB decided to continue the fixed rate tender procedure with full allotment for all main refinancing opera- } \\
\text { tions, special term refinancing operations and supplementary and regular longer term refinancing operations } \\
\text { for as long as needed }\end{array}$ \\
\hline 19-Mar-09 & ECB decided to continue US dollar liquidity providing operations \\
\hline 6-Apr-09 & ECB decided to establish a temporary reciprocal currency arrangement with the FED \\
\hline 7-May-09 & $\begin{array}{l}\text { ECB decided to purchase euro-denominated covered bonds issued in the euro area (CBPP1) and to conduct } \\
\text { liquidity providing longer term refinancing operations }\end{array}$ \\
\hline 4-Jun-09 & ECB decided upon technical modalities of CBPP1 \\
\hline 25-Jun-09 & ECB decided to extend the liquidity swap arrangements with the FED \\
\hline 2-Jul-09 & ECB started with the purchases of covered bonds (CBPP1) \\
\hline 24-Sep-09 & ECB decided to continue US dollar liquidity providing operations \\
\hline 20-Nov-09 & ECB amends rating requirements for asset-backed securities in Eurosystem credit operations \\
\hline 3-Dec-09 & $\begin{array}{l}\text { ECB decided to continue conducting its main refinancing operations as fixed rate tender procedures with } \\
\text { full allotment for as long as needed, and to enhance the provision of longer term refinancing operations. }\end{array}$ \\
\hline 4-Mar-10 & $\begin{array}{l}\text { ECB decided to continue conducting its main refinancing operations as fixed rate tender procedures with } \\
\text { full allotment for as long as needed, and to variable rate tender procedures in the regular } 3 \text { month longer } \\
\text { term refinancing operations. }\end{array}$ \\
\hline 10-May-10 & $\begin{array}{l}\text { ECB decided to proceed with the SMP, to reactivate the liquidity swap lines with the FED,to adopt a fixed } \\
\text { rate tender procedure with full allotment in the regular } 3 \text { month longer term refinancing operations and to } \\
\text { conduct new special longer term refinancing operations }\end{array}$ \\
\hline 10-Jun-10 & $\begin{array}{l}\text { European Central Bank has today decided to adopt a fixed rate tender procedure with full allotment in the } \\
\text { regular three-month longer-term refinancing operations }\end{array}$ \\
\hline 28-Jul-10 & ECB reviews risk control measures in its collateral framework \\
\hline 2-Sep-10 & $\begin{array}{l}\text { The Governing Council of the European Central Bank (ECB) has today decided to continue to conduct } \\
\text { its main refinancing operations (MROs) as fixed rate tender procedures with full allotment for as long as } \\
\text { necessary and to conduct the 3-month longer-term refinancing operations }\end{array}$ \\
\hline 2-Dec-10 & $\begin{array}{l}\text { The Governing Council of the European Central Bank (ECB) has today decided to continue conducting its } \\
\text { main refinancing operations (MROs) as fixed rate tender and to procedures with full allotment for as long } \\
\text { as necessary and to conduct the three-month longer-term refinancing operations }\end{array}$ \\
\hline 16-Dec-10 & $\begin{array}{l}\text { The Governing Council of the European Central Bank (ECB) has decided to establish loan-by-loan infor- } \\
\text { mation requirements for asset-backed securities (ABSs) in the Eurosystem collateral framework }\end{array}$ \\
\hline 21-Dec-10 & $\begin{array}{l}\text { ECB decided to continue to conduct US dollar liquidity-providing operations with a maturity of seven } \\
\text { days. These Eurosystem operations will continue to take the form of repurchase operations against eligible } \\
\text { collateral and will be carried out as fixed rate tenders with full allotment }\end{array}$ \\
\hline 3-Mar-11 & $\begin{array}{l}\text { The Governing Council of the European Central Bank (ECB) has today decided to continue conducting } \\
\text { its main refinancing operations (MROs) as fixed rate tender procedures with full allotment for as long as } \\
\text { necessary and to conduct the three-month longer-term refinancing operations }\end{array}$ \\
\hline 9-Jun-11 & $\begin{array}{l}\text { ECB decided to continue conducting its main refinancing operations (MROs) as fixed rate tender procedures } \\
\text { with full allotment for as long as necessary and to to conduct the three-month longer-term refinancing } \\
\text { operations }\end{array}$ \\
\hline 29-Jun-11 & ECB decided to to extend the liquidity swap arrangements with the Federal Reserve \\
\hline 4-Aug-11 & $\begin{array}{l}\text { ECB decided to conduct a liquidity-providing supplementary longer-term refinancing operation (LTRO) with } \\
\text { a maturity of approximately six months. The operation will be conducted as a fixed rate tender procedure } \\
\text { with full allotment. ECB also decided to continue conducting its MROs as fixed rate tender procedures with } \\
\text { full allotment for as long as necessary }\end{array}$ \\
\hline 8-Aug-11 & The Governing Council decided to relaunch the SMP for Italy and Spain after a period of inactivity \\
\hline 25-Aug-11 & ECB decided to extend the liquidity swap arrangement with the Bank of England \\
\hline 15-Sep-11 & ECB decided to conduct US dollar liquidity providing operations \\
\hline
\end{tabular}




\begin{tabular}{|c|c|}
\hline \multicolumn{2}{|c|}{ Continuation of Table B.1 } \\
\hline Announcement date & Announcement description \\
\hline $6-$ Oct-11 & $\begin{array}{l}\text { ECB decided to launch a new covered bond purchase programme (CBPP2) and to decided to conduct } \\
\text { two longer-term refinancing operations (LTROs), one with a maturity of approximately } 12 \text { months and the } \\
\text { other with a maturity of approximately } 13 \text { months. The operations will be conducted as fixed rate tender } \\
\text { procedures with full allotment }\end{array}$ \\
\hline $3-N o v-11$ & $\begin{array}{l}\text { the Governing Council of the European Central Bank (ECB) decided today upon the technical modalities } \\
\text { of the CBPP2 programme }\end{array}$ \\
\hline $30-$ Nov-11 & $\begin{array}{l}\text { ECB decided in cooperation with other banks the establishment of a temporary network of reciprocal swap } \\
\text { lines }\end{array}$ \\
\hline 8-Dec-11 & $\begin{array}{l}\text { The Governing Council announced } 2 \text { three-year LTROs5 and decided on additional enhanced credit support } \\
\text { measures to support bank lending and liquidity in the euro area money market }\end{array}$ \\
\hline 16-Dec-11 & $\begin{array}{l}\text { The European Central Bank (ECB) has decided to conduct two one-day liquidity-providing fine-tuning } \\
\text { operations (FTOs). }\end{array}$ \\
\hline 6-Jun-12 & $\begin{array}{l}\text { ECB decided to continue conducting its main refinancing operations (MROs) as fixed rate tender procedures } \\
\text { with full allotment for as long as necessary and to conduct the three-month longer-term refinancing operations }\end{array}$ \\
\hline 22-Jun-12 & ECB takes further measures to increase collateral availability for counter parties \\
\hline 6-Sep-12 & $\begin{array}{l}\text { ECB started Outright Monetary Transactions Programme and decided on additional measures on collateral } \\
\text { availability }\end{array}$ \\
\hline 12-Sep-12 & ECB extends the swap facility agreement with the Bank of England \\
\hline 6-Dec-12 & $\begin{array}{l}\text { The Governing Council of the European Central Bank (ECB) has today decided to continue conducting } \\
\text { its main refinancing operations (MROs) as fixed rate tender procedures with full allotment for as long as } \\
\text { necessary and to conduct the three-month longer-term refinancing operations }\end{array}$ \\
\hline 13-Dec-12 & ECB extends the existing swap arrangements with other central banks \\
\hline 21-Feb-13 & ECB announced the details on securities holdings acquired under the Securities Markets Programme \\
\hline 22-Mar-13 & ECB announces changes to the use as collateral of certain uncovered government-guaranteed bank bonds \\
\hline 2-May-13 & $\begin{array}{l}\text { The Governing Council of the European Central Bank (ECB) has today decided to continue conducting } \\
\text { its main refinancing operations (MROs) as fixed rate tender procedures with full allotment for as long as } \\
\text { necessary and to conduct the three-month longer-term refinancing operations }\end{array}$ \\
\hline 18-Jul-13 & ECB further reviews its risk control framework allowing for a new treatment of asset-backed securities \\
\hline 27-Sep-13 & ECB adopts decisions to follow up on the review of its risk control framework \\
\hline 10-Oct-13 & ECB and the People's Bank of China establish a bilateral currency swap agreement \\
\hline 31-Oct-13 & ECB establishes standing swap arrangements with other central banks \\
\hline 22-Nov-13 & ECB suspends early repayments of the three-year LTROs during the year-end period \\
\hline 24-Jan-14 & US dollar liquidity-providing operations as of 1 February 2014 \\
\hline 5-Jun-14 & $\begin{array}{l}\text { The Governing Council of the ECB has today decided to continue conducting its main refinancing operations } \\
\text { (MROs) as fixed rate tender procedures with full allotment for as long as necessary. And the Governing } \\
\text { Council has decided to suspend the weekly fine-tuning operation sterilizing the liquidity injected under the } \\
\text { Securities Markets Programme. It also decided to conduct a series of TLTROs and announce for the first } \\
\text { time that the deposit facility rate would be below zero. }\end{array}$ \\
\hline 17-Jun-14 & ECB extends US dollar liquidity-providing operations beyond 31 July 2014 \\
\hline 3-Jul-14 & ECB announces further details of the targeted longer-term refinancing operations \\
\hline 29-Jul-14 & ECB publishes legal act relating to TLTRO (I) \\
\hline 4-Sep-14 & $\begin{array}{l}\text { The Governing Council set deposit facility rate even more negative }(-0.20) \text {. The Governing Council of } \\
\text { the European Central Bank (ECB) has decided to modify the loan-level reporting requirements for asset- } \\
\text { backed securities (ABSs). Additionally, the Governing Council has decided that, as of } 1 \text { October } 2014 \text {, the } \\
\text { Eurosystem may temporarily accept non-compliant auto loan, leasing, consumer finance and credit card } \\
\text { ABSs as eligible collateral }\end{array}$ \\
\hline 16-Sep-14 & Announcement of the first TLTRO (I) \\
\hline 18-Sep-14 & The ECB allots $€ 82.6$ billion in first TLTRO \\
\hline 2-Oct-14 & ECB announces operational details of asset-backed securities and covered bond purchase programmes \\
\hline $30-O c t-14$ & ECB appoints executing asset managers for the ABS Purchase Programme \\
\hline 7-Nov-14 & ECB suspends early repayments of the three-year LTROs during the year-end period \\
\hline 9-Dec-14 & Announcement of the second TLTRO (I) \\
\hline 11-Dec-14 & The ECB allots $€ 129.8$ billion in second TLTRO (I) \\
\hline
\end{tabular}




\begin{tabular}{|c|c|}
\hline \multicolumn{2}{|c|}{ Continuation of Table B.1 } \\
\hline Announcement date & Announcement description \\
\hline 22-Jan-15 & $\begin{array}{l}\text { ECB announced an expanded asset purchase program and announces a modification to the interest rate } \\
\text { applicable to future targeted longer-term refinancing operations }\end{array}$ \\
\hline 17-Mar-15 & Announcement of the third TLTRO (I) \\
\hline 19-Mar-15 & The ECB allots $€ 97.8$ billion in third TLTRO (I) \\
\hline 16-Jun-15 & Announcement of the fourth TLTRO (I) \\
\hline 18-Jun-15 & The ECB allots $€ 73.7$ billion in fourth TLTRO (I) \\
\hline 22-Sep-15 & Announcement of the fifth TLTRO (I) \\
\hline 23-Sep-15 & Eurosystem adjusts purchase process in ABS programme \\
\hline 24-Sep-15 & The ECB allots $€ 15.5$ billion in fifth TLTRO (I) \\
\hline 11-Oct-15 & Increase in PSPP issue share limit enlarges purchasable universe \\
\hline 3-Dec-15 & The Governing Council set deposit facility rate even more negative $(-0.30)$ \\
\hline 9-Dec-15 & Announcement of the sixth TLTRO (I), The ECB started applying the -0.30 deposit facility rate. \\
\hline 11-Dec-15 & The ECB allots $€ 18.3$ billion in sixth TLTRO (I) \\
\hline 10-Mar-16 & $\begin{array}{l}\text { The ECB announced new series of TLTROs (II). The ECB added the CSPP to the APP. The Governing } \\
\text { Council set deposit facility rate even more negative }(-0.40)\end{array}$ \\
\hline 16-Mar-16 & The ECB started applying the -0.40 deposit facility rate. \\
\hline 22-Mar-16 & Announcement of the seventh TLTRO (I) \\
\hline 24-Mar-16 & The ECB allots $€ 7.3$ billion in seventh TLTRO (I) \\
\hline 21-Apr-16 & The ECB announced details of the CSPP \\
\hline 3-May-16 & ECB publishes legal act relating to the new series of TLTROs (II) \\
\hline 2-Jun-16 & ECB announces remaining details of the corporate sector purchase programme \\
\hline 8-Jun-16 & The ECB started CSPP \\
\hline $5-O c t-16$ & Changes to collateral eligibility criteria and risk control measures for unsecured bank bonds \\
\hline $3-\mathrm{Nov}-16$ & ECB reviews its risk control framework for collateral assets \\
\hline 8-Dec-16 & ECB adjusts parameters of its asset purchase programme (APP). \\
\hline & Eurosystem introduces cash collateral for PSPP securities lending facilities \\
\hline 15-Dec-16 & Eurosystem adjusts purchase process in ABS purchase programme (ABSPP) \\
\hline
\end{tabular}

Table B.2: Number of Factors and Rsquare

\begin{tabular}{cc}
\hline \# Factors & Rsquare \\
1 & 0.451 \\
2 & 0.643 \\
3 & 0.693 \\
4 & 0.719 \\
5 & 0.756 \\
6 & 0.783 \\
7 & 0.803 \\
8 & 0.818 \\
9 & 0.832 \\
10 & 0.843 \\
\hline \hline
\end{tabular}




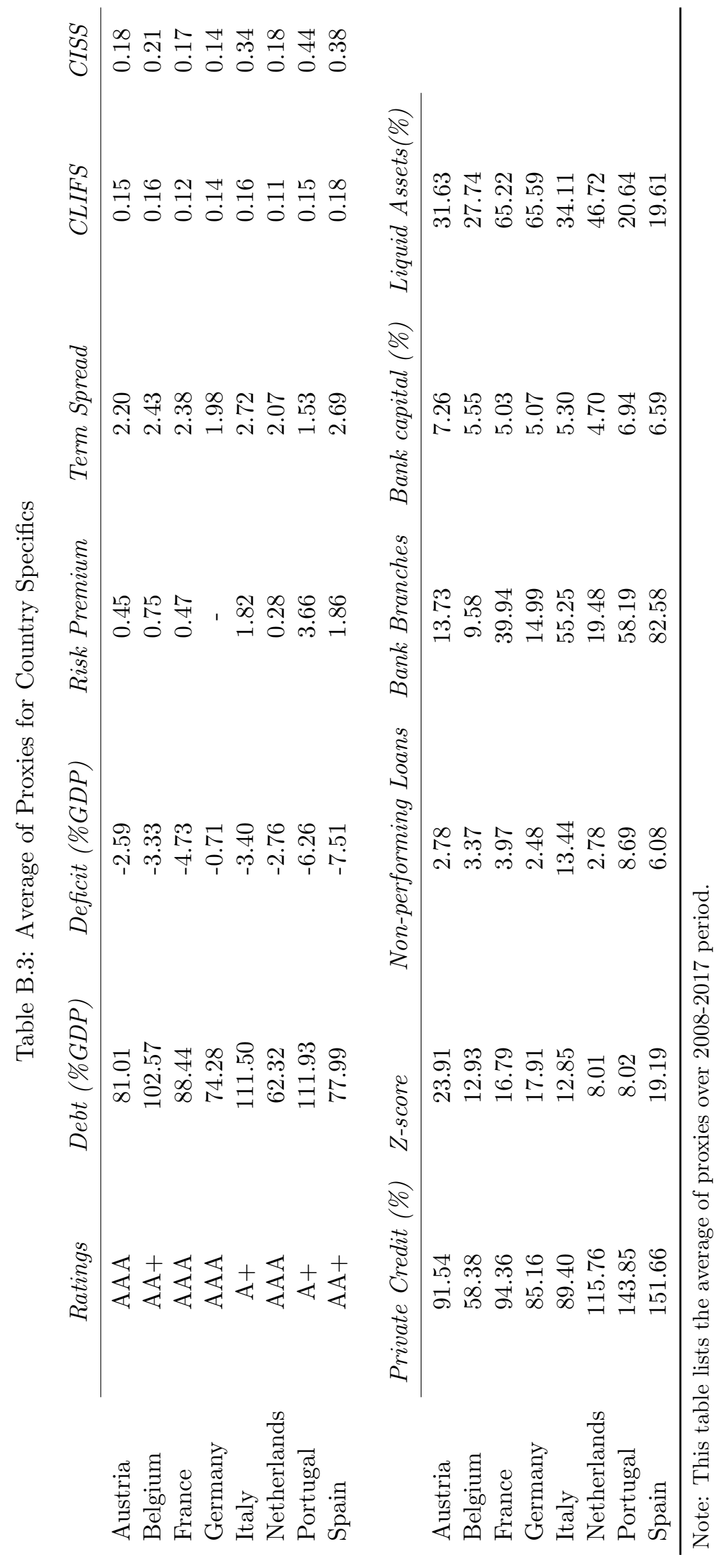



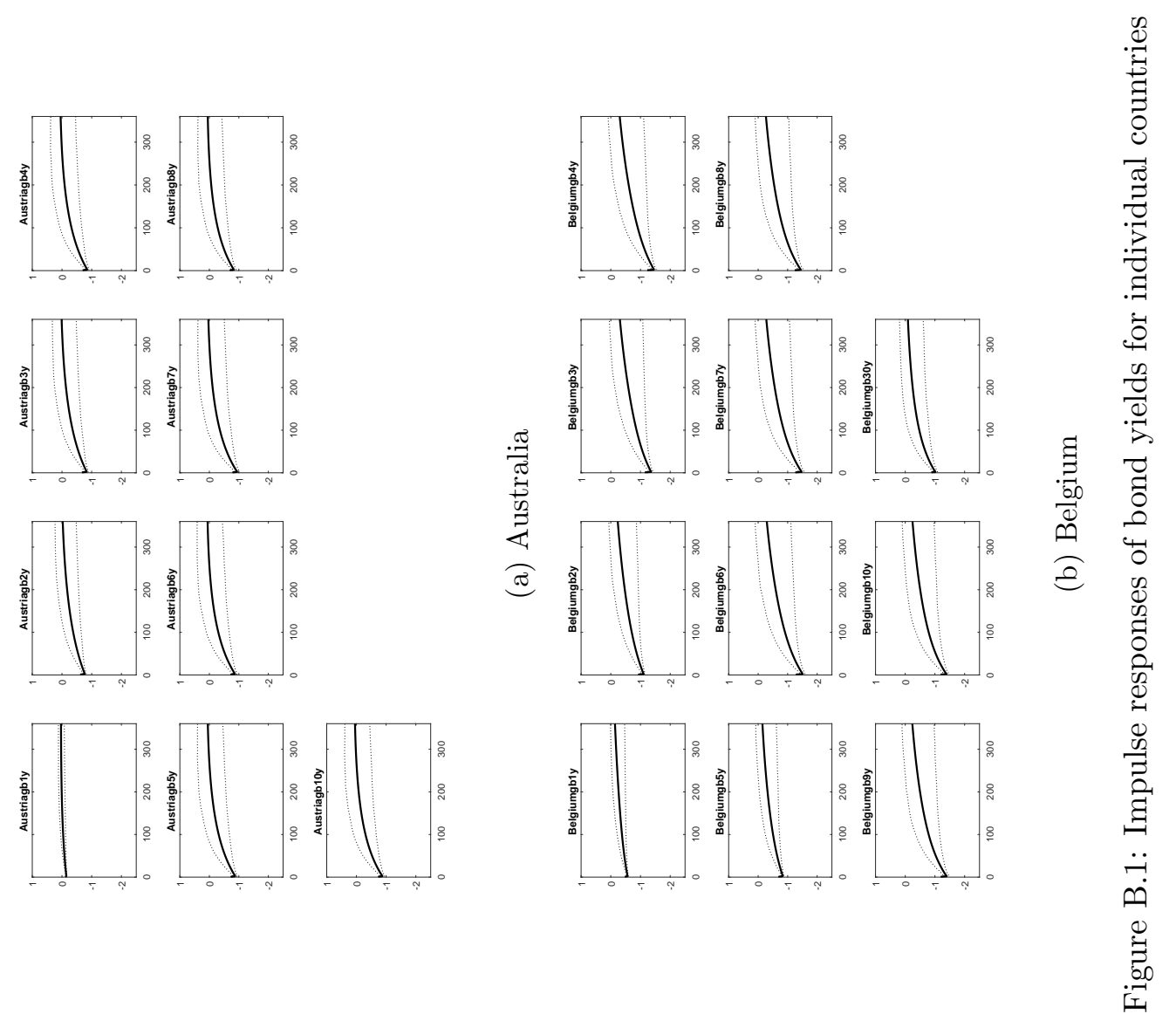

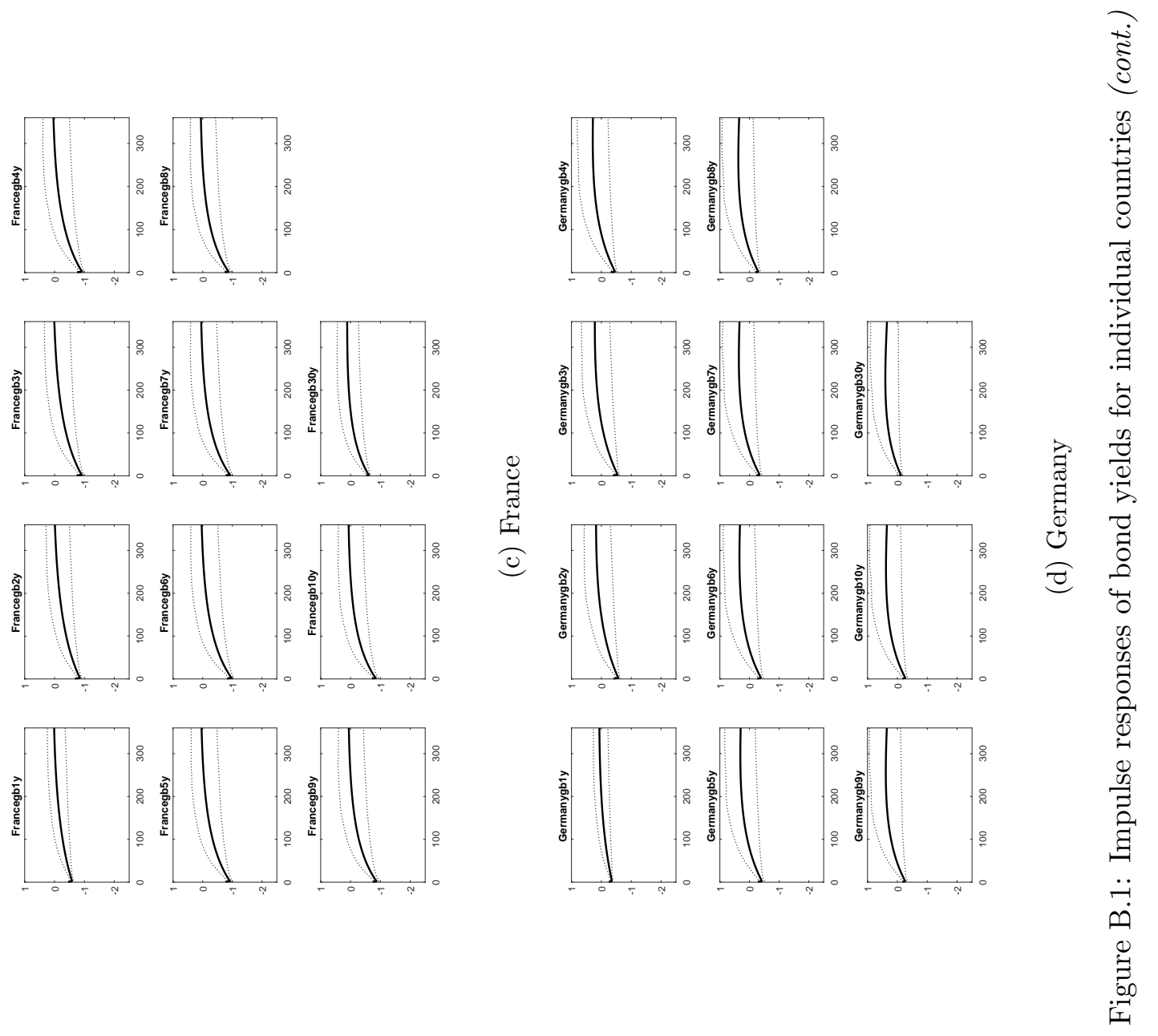

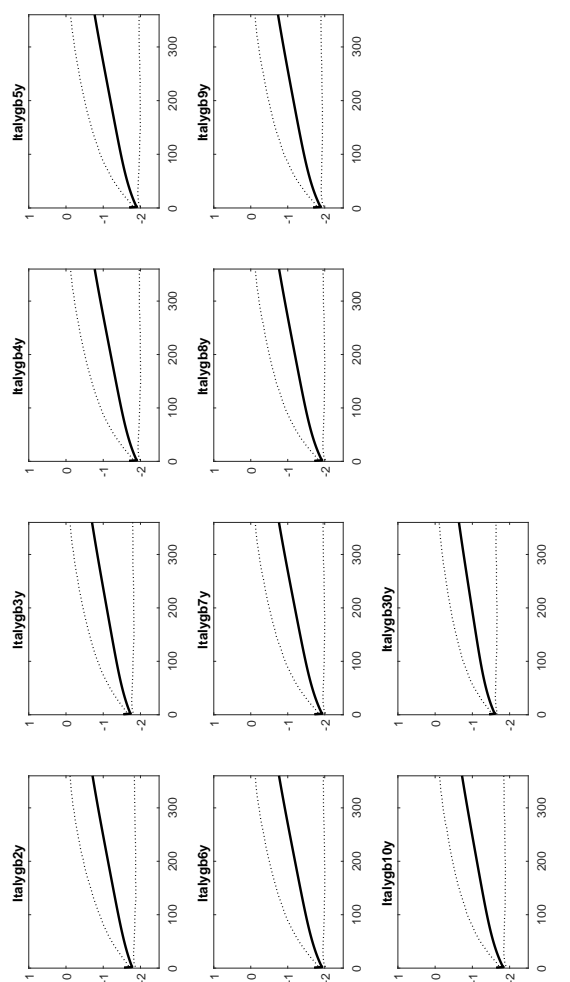
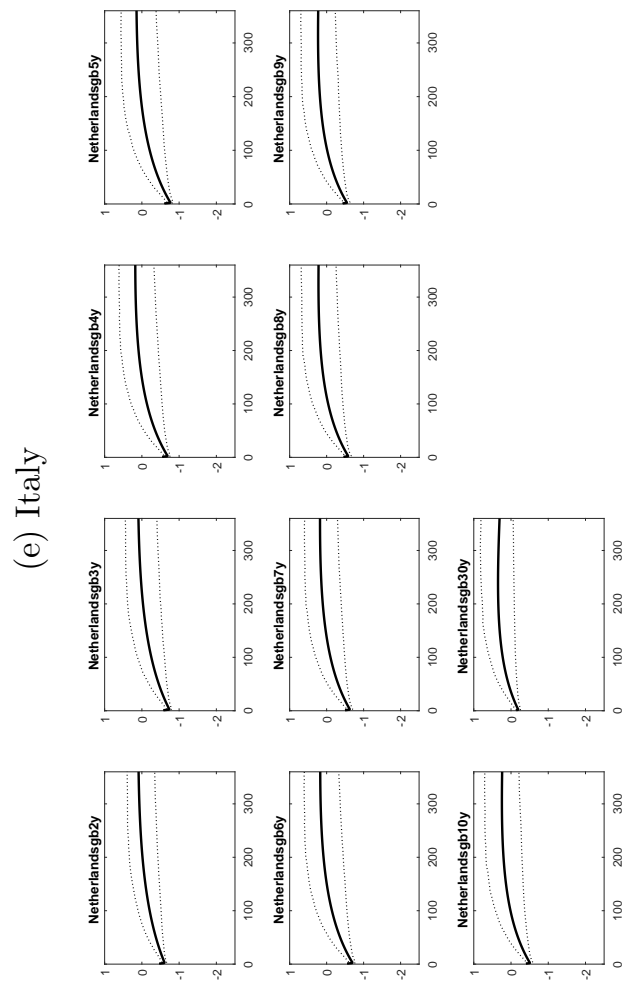

ङ્.

.

్ㅗㅇ

苂

:

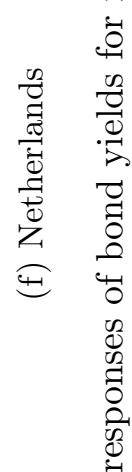

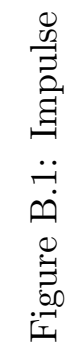



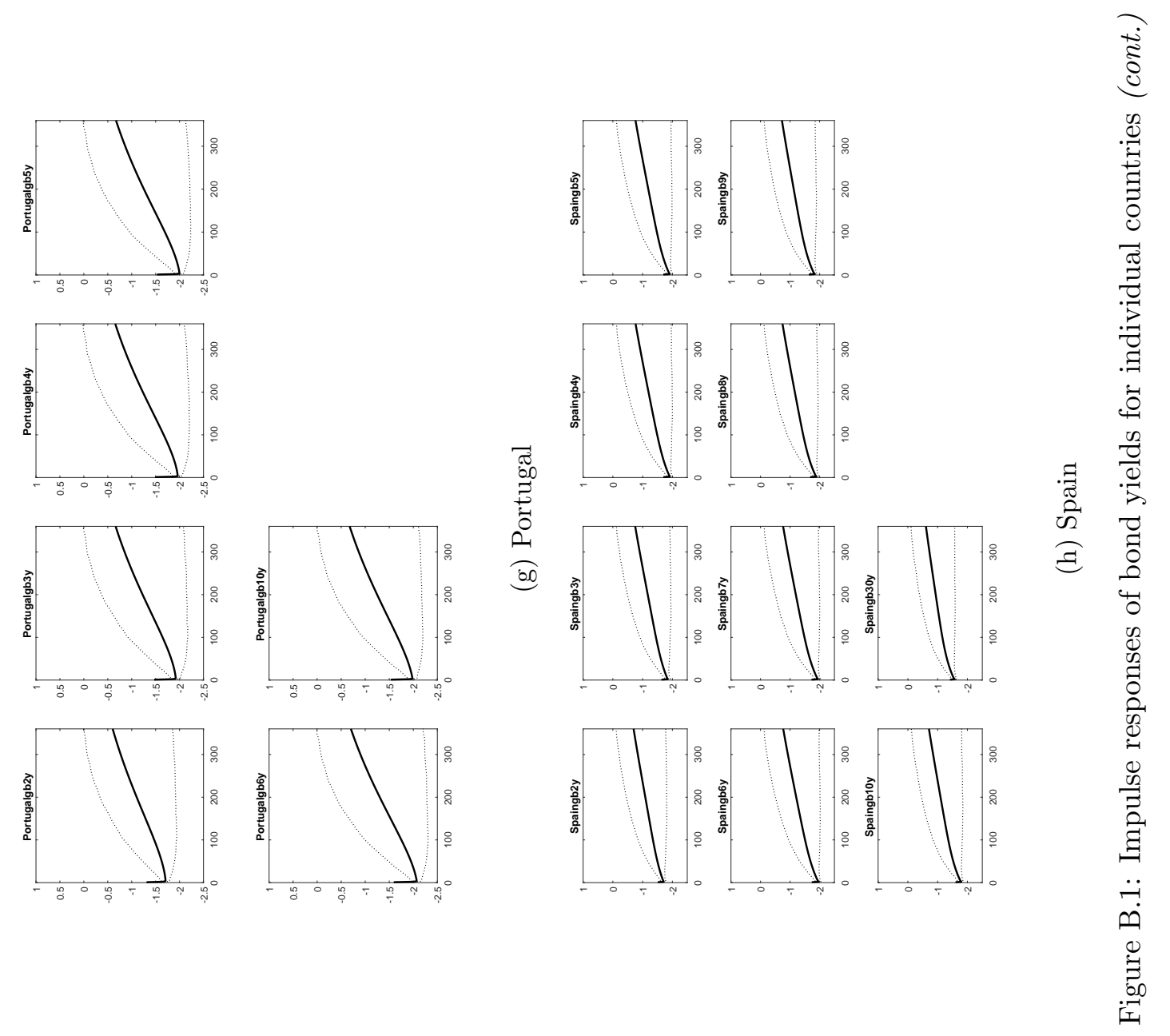